\title{
The Hero Fallen: \\ Zhang Yimou and the Question of Unstable Authorship
}

By

Mark Brent Ellsworth

\begin{abstract}
A thesis
submitted to Victoria University of Wellington

in fulfillment of the requirements for the degree of

Masters of Arts

in Film
\end{abstract}

Victoria University of Wellington

2013 


\begin{abstract}
When Zhang Yimou's film, Hero (2002), was released it was one of the most successful Chinese films ever screened in American theaters. While many critics applauded the film's aesthetics, other reviewers condemned the film for undermining the political potency of Zhang's early films and promoting a fascist ideology. The interpretation of Hero as fascist propaganda has incited a controversy over the reception of the film that has penetrated academic as well as journalistic circles. A close look at this controversy reveals that there has been a tendency in the West to read a film and filmmaker in a manner predetermined by where they are from and the discourse that already exists. This 'auto-reading' or 'auto-positioning' tendency is symptomatic of a reliance on discourses of authorship and national cinema. The manner in which these discourses have permeated the way that the West has responded to Zhang and his films has given rise to three 'recurring motifs:' aesthetic virtuosity, cultural authenticity, and national politics. These motifs are characteristics which have been repeated so often that they became defining qualities of his authorship and have often determined the interpretation of his films.

This thesis involves a mapping of the critical reception of Hero and the way it relates to Zhang's prior work, his auteur status, and his relationship to the Chinese nation-state. Specifically, this thesis examines how the discursive reception of Zhang's career and films provided the context out of which emerged the framework that justifies reading the film as fascist. Tracing the recurring motifs throughout the Western reception of Zhang's films reveals the problematics of the reliance on the discourses of authorship and national cinema. This thesis will also explore Hero directly to investigate how the film's ambiguities have contributed to the reading of the film as fascist but also how ambiguity facilitates the potential to interpret other meanings in the film.
\end{abstract}




\section{Table of Contents}

\section{Acknowledgements iii \\ Introduction 1 \\ Chapter One $\quad 10$}

The Genesis of Zhang's Authorship

Chapter Two 27

Hero's Reception and the Fascist Framework

Chapter Three $\quad 44$

Alternative Interpretations of Hero

Conclusion 62

Appendix $\quad 64$

Zhang Yimou and His Films

Works Cited 66 


\section{Acknowledgements}

The completion of this thesis has been an arduous journey full of many ups and downs, pitstops and pitfalls that have challenged, inspired, and matured my academic progress. I wish to acknowledge the support and encouragement of all those who have assisted me in this process, directly or indirectly. I especially like to acknowledge the assistance of my supervisors at Victoria University of Wellington: Sean Redmond for his enthusiastic help with finding my initial footing at the start of this journey; and Miriam Ross for her invaluable guidance thru the final stages of my writing.

Thanks also to the other film faculty, administrators, and postgraduate colleagues with whom I had the regular pleasure to work and whose encouragement was so often a boon. I will not soon forget the supportive discussions held with fellow students over a friendly meal, or the times spent sharing and discussing each others work at postgraduate research meetings. I am indebted to the faculty and staff for the confidence and trust bestowed on me and the opportunities I had to lecture and to tutor.

Many thanks to those family and friends who tolerated and who endured long discussions about a film they have not seen. To my wife and kids, thanks for lifting me up in times of discouragement and celebrating, with me, those little victories. 


\section{Introduction}

In 2008, Zhang Yimou was at the center of the world's attention as the director of the opening and closing ceremonies for the Beijing Olympics. When journalists wrote about Zhang's Olympic ceremonies, his career as a filmmaker and his relationship to China was often foregrounded and emphasized, qualifying his ceremonies in the context of the international distinction he had garnered as a film director. It was not just Zhang Yimou who directed the opening and closing ceremonies, it was “Zhang Yimou, China’s most famous filmmaker” (Bristow). Zhang Yimou was not simply the director of the ceremonies who also happened to be a film director; journalists have intimated that the two pursuits were intrinsically connected. Writing for Times Magazine, Steven Spielberg asserted that Zhang's Olympic ceremonies were an extension of Zhang's filmmaking career and Zhang's personal destiny would be realized in the presentation of the Chinese nation to the world; "every movie he had ever made would be a luminous precursor to what was surely going to be a personal journey of destiny. Zhang would be the creator-director of the Olympic ceremonies, with the honor of putting on what would become the greatest show on earth, with China at center stage." Reading Spielberg's assertion in the context of Zhang's auteur status foregrounds the way that discourse has positioned Zhang and his films in a direct relationship to the Chinese nation-state. This discursive positioning accompanied Zhang's auteur status from the very beginning of his film directing career and reached a critical juncture with the release of his eleventh film, Hero (2002), which was met by a controversy about the film's perceived politics. The journalistic and academic response to the film, and this controversy, was so extensive that one writer described it as having "filled the sky and covered the ground" (Zhang Jianyong qtd. in Larsen 181). While Zhang's Olympic ceremonies had re-confirmed his presence on the international stage, the response to his ceremonies re-centered the discussion of Zhang's career on the debate surrounding Hero's controversial politics. The connection between Zhang's ceremonies and his film career highlights the persistent importance of authorship discourse. This thesis returns to Hero in order to examine how the reception of Zhang's work raises important questions about the function of discourse on auteurs and the manner in which their work is connected to issues of national identity in an international arena. A close inspection of the many responses to Hero reveals a fracturing in the discourse of Zhang's filmmaking career and how his authorship has been constructed. 
In 1982, many years before his Olympic ceremonies, Zhang began his film career as a cinematographer when he graduated from the Beijing Film Academy. Zhang, and those who graduated with him, would become known as the Fifth Generation of Chinese filmmakers: a designation referring to those who were the first to graduate from the academy after the Cultural Revolution had ended ${ }^{1}$. One and Eight (1984) was the Fifth Generation's first film. Upon its reception, writers in China and the West praised the "Chinese creativity" manifested by Zhang's cinematography (Brook 24). The same year as One and Eight, Zhang was cinematographer for Yellow Earth (1984), a film that was enthusiastically received with acclaim at various international film festivals. With the reception of their early films, the Fifth Generation demonstrated that their films were superior to the work of their predecessors and were as good as, if not better than, films from other countries (see Rayns 1-2). In 1987, Zhang made a career transition from cinematographer to director with Red Sorghum (1987), an award-winning portrayal of a strongwilled peasant woman doing her best to triumph against oppressive circumstances. Once he began directing films, the international reception of his earliest films generated a discursive interest where the discussion of Zhang as an author or auteur would find its genesis. Most often the interest in his career and its international visibility was based on the fact that he was Chinese, making films in and about China. As the number of films directed by Zhang grew, so did the international renown surrounding his authorship, winning prizes at film festivals and garnering accolades from critics across the globe ${ }^{2}$. It is little exaggeration to suggest that Zhang Yimou has been China's most popular, and most written about, filmmaker (See Bristow, also see Lu, “Zhang” 412).

Twenty years after graduating from the Beijing Film Academy, Zhang directed Hero and realized a long-time ambition to make a film in the wuxia genre (Cardullo 134). As a wuxia film, Hero was a significant departure from the films that Zhang had directed previously; the production design and staging was more spectacular, the narrative was more epic in scope, and it was produced on a much larger budget than any of his other films. Wuxia is a Chinese cross-media genre which has its origins in Chinese literature from the late Qing and early Republican era - around the turn of the twentieth century. Films in the wuxia genre are important for their contribution to Chinese national identity as a fantastical and spectacular "showcase of Chinese history... locating itself

\footnotetext{
${ }^{1}$ While 'Fifth Generation' is a term that generally refers to all those filmmakers who graduated in the same class, its use in scholarship and journalism most often relates specifically to a smaller group of prominent filmmakers who have received critical acclaim overseas - such as Chen Kaige, Tian Zhuangzhuang, and Zhang Yimou (Zhu 7, see also Chen and Haque).

${ }^{2}$ See Appendix for a brief chronology of Zhang's life and his films, including many of the awards that he and his films have received throughout his career. The chronology found in Appendix helpfully situates each film and major event in context with other events and films.
} 
within the historicist confines of the nation-state" (Teo, Chinese 172; see also Xu 30). The 'showcase' that wuxia films exhibit are chiefly characterized by their display of a particular martial arts action aesthetic, often set in a historical Chinese setting. In English these films are often referred to as 'swordplay' films or 'knight-errant' films which highlights two important characteristics of the genre: in wuxia stories, the sword is the predominant weapon of choice wielded by wandering knight-esque central characters. While wuxia is not exactly synonymous with European knight-errant tradition ${ }^{3}$, the translation is a suitable approximation. A more literal translation reveals that wuxia is a compound of $w u$ and xia: $w u$ meaning 'martial,' emphasizing militaristic warrior qualities; xia meaning 'valour,' emphasizing chivalry, honor, and gallantry (Teo, Chinese Martial 2). The characters of wuxia films, particularly the heroes and heroines - known as the xia - are very proficient with martial arts and the sword. Their fighting proficiency most often manifests as dance-like fighting technique which is in harmony with the natural environment, enabling them to defy gravity and float. The 'floating swordsman' quality of the genre is often what distinguishes wuxia from the gravitationally-challenged fist-fighting kung fu genre. ${ }^{4}$

Hero was Zhang's first wuxia film and represents the point where issues of the discourse of Zhang's filmmaking career became most pronounced. In order to make sense of the discourse surrounding Hero's reception and its position in Zhang's career, it is necessary to understand the plot of the film. Then, throughout this thesis, discussion and analysis of the various responses to the film, especially those that have addressed the plot directly, will be properly contextualized. Hero is set during China's Warring States Period - approximately 200 B.C.E. The title slides explain that "before China was one great country, it was divided into seven warring states. In the Kingdom of Qin was a ruthless ruler. He had a vision - to unite the land, to put an end, once and for all, to war." Nameless (Jet Li) is a warrior assassin with an elaborate plot to avenge the destruction of his family and village by killing Qin Shihuang 5 (Chen Dao Ming). Nameless' strategy is to create the appearance that he has slain Qin's enemies. Masquerading as a prefect from a province which is an ally to Qin, Nameless is welcomed to the emperor's palace as a hero. Once in the emperor's presence a dialogue begins. By law, no one is allowed to be closer than one

\footnotetext{
${ }^{3}$ For instance, European knights are often part of, or associated with, the aristocratic nobility while the wuxia 'knight' is a wandering member of the jinhua, or society's back-alleys and underground. See Teo's Chinese Martial, and Farquhar's "A Touch" for more on the differences between the two traditions.

${ }^{4}$ Wuxia is far more complex and dynamic than I have necessarily essentialized here. See Stephen Teo's Chinese Martial Arts Cinema: The Wuxia Tradition for in-depth history and breakdown of the rich genre.

5 The film is set at a time when Qin Shihuang was the ruler of the Kingdom of Qin. From this position he conquered the other kingdoms to create a Chinese empire and become known as China's first emperor. I will use 'emperor' to refer to Qin, except when using quotes from the film or other writers that refer to him as 'king.'
} 
hundred paces from the emperor - it is revealed that this law is in place for the emperor's safety because of previous assassination attempts. The dialogue between Nameless and Qin is focused on the stories of Nameless' success in killing Qin's most notorious enemies: the assassins Sky (Donnie Yen), Flying Snow (Maggie Cheung), and Broken Sword (Tony Leung). As these stories are told the film presents Nameless' encounters in flashback, each story having its own saturated monocolor design palette. As it is revealed that Nameless was successful at killing an assassin, he is permitted to move closer and closer until he is ten paces away from the emperor's throne - the reward for Nameless' heroic service.

In the first story, presented with a grey palette, Nameless confronts Sky at a chess house. Demonstrating the exceptional swordsman skills that Nameless has developed, he kills Sky. The next flashback story soon begins as Nameless explains to Qin how he turned Flying Snow and Broken Sword against each other by inciting jealousy and hatred between the two of them. This story is told in vibrant red - red clothes, red wood walls, red curtains, red paint, etc. Nameless finds Broken Sword and Flying Snow hiding out in a calligraphy school. When he arrives, Nameless asks Broken Sword to create a scroll of the twentieth variation of the word 'sword.' Presenting Sky's spearhead to Broken Sword and Flying Snow, Nameless turns the pair against each other by delivering a fictitious message of love from Sky to Flying Snow. In impassioned rage, Flying Snow kills Broken Sword and the following morning, Nameless kills Flying Snow. At the conclusion of the red story, the emperor, surmising that Nameless' story is a lie, retells the story the way he thinks it really happened. Presented in a blue palette, the emperor's story proposes that Nameless had constructed this elaborate 'hero' guise in concert with the other assassins as a ruse to get within ten paces of the emperor. Then within ten paces, Qin guessed that Nameless would be close enough to kill the emperor using a special sword maneuver that Nameless had perfected.

Qin's realization of the truth of Nameless' motive comes too late, the assassin is already within range to kill the emperor. But Nameless pauses and explains to the emperor that Broken Sword tried to stop Nameless from killing Qin. In a white flashback story, Broken Sword confronts Nameless and attempts to persuade Nameless to give up his vengeance quest by introducing Nameless to the two-word ideal of tian xia, or 'our land.' It is with this revelation that the emperor understands that Broken Sword, his great enemy, understood the emperor's objective of unifying all of the land. Qin, content that he has been understood, surrenders his sword to Nameless so that Nameless might succeed with his assassination. Then, Nameless executes his special maneuver but, at the last minute, decides not to kill the emperor. Instead he harmlessly jabs the pommel of the 
sword into Qin's back, drops the sword and walks away from the throne. As he walks away, the emperor's court persuades him to execute the assassin. Under a barrage of arrows, Nameless dies.

The analysis central to this thesis stems from my own experience of Hero's release in America. Having enjoyed other Zhang Yimou films, I looked forward to Hero with great anticipation. Shortly after watching Hero I quickly noticed a disparity between my experience - a mixture of fascination for the film's aesthetics and my own interpretation that the film embodied a complex and profound promotion of peace - and a critical response by some Western writers who suggested that the film was fascist propaganda. Vivian Lee wrote about the division that emerged among the responses to Hero which mostly accounts for the discord of my own experience, "while individual responses vary according to personal taste, cultural background and expectations, there is a general dividing line between appreciation of the film's visual beauty and dismay over its propaganda." At least initially, there were two essential reactions to the film, 1) that it was a visually stunning film, an aesthetic masterpiece, or 2) that Hero's controversial politics is evidence that Zhang has succumbed to the 'temptations of fascism.' This argument that the film promotes fascism fueled a controversy over the film's politics and it is the interpretation at the center of this argument that primarily interests the present investigation. In fact, the controversy incited by this argument appears to be a significant reason as to why the film has sustained such potent visibility in the global marketplace - being written about and talked about up to the time of writing this thesis.

To understand the controversy and the existence of the argument which reads the film as fascist propaganda, this thesis is a mapping of the critical reception of Hero and the way it relates to Zhang's prior work, his auteur status, and his relationship to Chinese national cinema. I will be using the terms 'fascist argument' and 'fascist framework' to represent those criticisms, reviews, and analyses which have advocated the interpretation of Hero as a film that represents Zhang succumbing to the pressures of the Chinese government and promoting a fascist ideology. This thesis is not meant as merely a criticism of those writers who promote the fascist argument, but it is an investigation to understand how the discursive reception of Zhang's career and films provided the context out of which the fascist argument emerged.

When Hero was released, a reliance on the pre-existing discursive construction of Zhang's authorship and his relationship to the Chinese nation-state had determined that Hero was interpreted as necessarily representing a submission to the Chinese government. While Zhang's authorship has always relied heavily on his perceived relationship to the Chinese nation-state, the way that Hero was interpreted as promoting fascism indicates that Zhang's perceived relationship to the nationstate had undergone a discursive shift from his previous oeuvre; Hero has represented a 'break' in 
Zhang's authorship. Zhang, once a subversive filmmaker, with Hero, was thought to have become submissive to the Chinese Communist Party and a promoter of fascism. As Michael Berry has observed, Zhang "went from being this renegade making films that were banned and an eyesore for the Chinese government to kind of being a pet of the government, in some people's eyes... it's almost a complete turnaround from his early days" (qtd. in Barboza). This thesis seeks to understand why this 'break' occurred through the investigation of the Western discourse of Zhang Yimou and Hero.

In spite of the break that Hero has represented, there are three common characteristics found in the discourse of Zhang's films, before and after Hero, that have been important to the interpretation of his films and the construction of his authorship: virtuosic aesthetics, cultural authenticity, and national politics. These characteristics, what I will refer to as the 'recurring motifs' of Zhang's authorship, are found throughout the many responses to Zhang and his films analysis, interviews, reviews, etc. While the recurring motifs do not always manifest together in each response, traces and semblances of at least one of these three basic qualities are found throughout most of the responses which contribute to the discourse of Zhang and his films. Importantly these motifs, which contributed to defining Zhang as an auteur, have played an important role in also circumscribing Zhang's relationship to the nation-state. Prior to Hero, or preHero, those motifs were interpreted as defining Zhang as subversive to the Chinese government. After Hero, or post-Hero, those motifs provided evidence - to those who endorsed the fascist framework - for the allegation that Zhang was then submissive to the government.

Examining the motifs of Zhang's authorship uncovers inherent problems when Western writers experience a film from a well-known Chinese director. Often they tend to auto-read based on an auteur's discursive construction or to auto-position based on a discursive relationship to the nation-state. The concepts of auto-reading and auto-positioning describe the tendencies of Western writers to read a film and filmmaker in a manner predetermined by where they are from and the discourse that already exists - this will be investigated more in-depth in chapter one. The challenge becomes to not only interrogate those readings and those discursive propensities, but to also reinvestigate the text and attempt to discover what other meaning it may offer.

In "Chapter One: The Genesis of Zhang's Authorship," Foucault's notion of the 'authorfunction' will provide the foundation to analyze the creation, the construction, and the emergence of what several have called "the myth of Zhang Yimou" (Zhen 173, also Lu "Chinese Film" 125) - the constructed auteur status, or authorship, of the "best-known contemporary Chinese filmmaker both inside and outside China (Lu, “Zhang” 412).” Foucault's 'author-function' reveals the tendency of 
authorship discourse to dictate and determine the characteristics and qualities of the auteur. This chapter traces the three motifs of Zhang's authorship to discover how the discourse of Zhang's filmmaking career contributed to the construction of his auteur status in a manner that determined the reception of his films. This chapter also briefly explores what could be called the 'lost texts' of Zhang Yimou. There have been many texts and works, created by Zhang, that have often been excluded from his authorship construction. If included, their existence has usually been dismissed and not considered in determining the characteristics of Zhang's auteur style. Investigating these lost texts produces evidence that the discourse of authorship has some inherent problematics. The focus of this first chapter is the analysis of the discursive environment of authorship upon which the fascist framework has relied and out of which it had emerged.

In the next chapter, "Chapter Two: Hero's Reception and the Fascist Framework," I will explore the environment of Hero's release to understand the controversy that arose. I will also analyze Evans Chan's influential review of the film. His review, "Zhang Yimou's Hero and the Temptations of Fascism" summarized the objections of many international film scholars and critics. While the fascist argument has had many proponents, Chan's article has been one of the most often cited. Chan insisted that "the impulse behind the film can be called fascist - it promotes a personality cult that claims oneness with the progression of the national destiny, and which inspires willful, bloody sacrifices" (18). Reading the film as fascist emphasizes and prioritizes the film's perceived relationship to the nation-state. This is symptomatic of how Zhang's discursive position in Chinese national cinema resulted in the tendency to pre-configure his films as necessarily for or against the Chinese government. As the fascist framework promoted a fascist reading of Hero, the motifs of Zhang's authorship were reconfigured by the argument, having undergone a shift in order to explain the fascist interpretation. Complimenting Chapter One, this chapter will trace the shifted motifs while investigating the fascist framework's response to Hero 's release. To better understand the justifications of the fascist framework's allegations against the film, this chapter will also investigate the discourses of national cinema and the discursive relationship of Zhang and his films to the Chinese nation-state.

Once the frameworks and discourses are deconstructed and analyzed in the first and second chapters, "Chapter Three: Alternative Interpretations of Hero" revisits Hero using alternative readings, those of other writers and my own analysis. Here I will investigate how alternative readings have produced approaches to the text that are outside the predetermining frameworks I have explored thus far. If the previous chapter demonstrated where the frameworks began to break down, this chapter is an attempt to explore the film outside the hegemony of those frameworks. 
Through a close examination of the film and a look at responses that were alternative to the fascist framework several important aspects of the film are revealed, aspects that were neglected or ignored because of assumptions made by the fascist argument. The alternative analyses explored in this chapter, and an understanding of the function of ambiguity in the film, help to expose a few of the problematic assumptions that the fascist argument makes. These problematic assumptions are symptomatic of the convenience of reading Hero in the context of a predetermining discourse of Zhang's auteur status or of a supposed 'National Cinema.'

It is useful here to discuss the parameters of my research. As Hero remains one of the more popular Chinese-language films ever to be screened in Western cinemas, the amount of academic and journalistic attention is quite extensive. As more writing about the film continues to be printed, it is necessary to delineate that research for this thesis covers only those books, articles, and essays printed or published prior to June 2010 - the point where the focus of my work shifted to writing. Also, of note, is that not all things written about Zhang Yimou or Hero falls into pro-fascist and anti-fascist categories. While I use as many writers as possible to explain the discursive construction of Zhang Yimou's authorship via 'recurring motifs,' my analysis of the fascist framework is not meant to be all inclusive of everyone who has ever written about Chinese cinema, Zhang Yimou, or even Hero. The fascist argument is only one approach to the interpretation of Hero, yet its pervasiveness is such that nearly everyone who has written about Hero and Zhang Yimou have been obliged to either support or reject the fascist argument, and must address the argument regardless of their position towards it.

Delineating a timeframe for the research conducted for this thesis is not the only parameter of this project. The lack of availability of some of Zhang's films has prohibited me from analyzing the totality of his career. For instance, the films Operation Cougar (1989) and Keep Cool (1997) are unavailable to Western markets, trying to find a copy of either of these films with English subtitles has been impossible. This limited availability of some of Zhang's films, indicates a discrimination that is determined by the commercial viability of the distribution of Zhang's films. It is of particular interest that those films that are unavailable to the West are precisely those that seem to be incompatible with his auteur construction as it has been perceived in the West - this is explored further in Chapter One. By utilizing the reviews and analyses of Zhang's films which have been published in the West - written in English, or translated into English - I am able to deconstruct the Western discourse and the way in which Zhang's authorship and relationship to the Chinese nation-state has been constructed. This, in turn, reveals how that construction has 
determined how the West has interpreted and received his films, particularly how Hero has been interpreted as mere fascist propaganda. 


\section{Chapter 1:}

\section{The Genesis of Zhang's Authorship.}

In 1988, Zhang's directorial debut, Red Sorghum (1987), was honored with the Golden Bear award at the Berlin International Film Festival, the first time that a Chinese-language film had received this award. This was the beginning of the international recognition that would establish Zhang as one of China's most pre-eminent filmmakers and the leading figure of the Fifth Generation. Following Red Sorghum's precedent for international recognition, Zhang's Ju Dou (1990) and Raise the Red Lantern (1991) were both honored separately as nominees for the Academy Award for Best Foreign Language film - Ju Dou was the first Chinese-language film to ever receive official recognition at the Academy Awards. These three films became known by critics and scholars as Zhang's 'Red Trilogy' due to their shared concern with national identity, landscape, and gender politics as well as for their formal similarities, particularly the predominant use of the color red responsible for the 'Red Trilogy' designation. As writers in the West responded to the Red Trilogy, Zhang was quickly initiated into the pantheon of international film directors who were designated, and studied, as auteurs: filmmakers who are acknowledged as being "the controlling intelligence behind the making of a film" (Wartenberg and Curran 91). As an auteur, Zhang's films would be read and categorized together as products of a single individual author, "an approach rarely afforded to (People's Republic of China) artists” (Zhang X., Postsocialism 289; Zhang Y., Screening 100; see also Lu, "National Cinema” 106).

Although Zhang had been a renowned cinematographer in the 1980s, it was the discourse surrounding his role as director of the Red Trilogy films which initially defined and circumscribed the characteristics and qualities of his auteur status. When writers began to respond to the films of Zhang, the director, it was common for them to incorporate biographical details from Zhang's life before he was a filmmaker in an attempt to understand and interpret his films. The incorporation of Zhang's life events into the analysis of his films has contributed to the development of Zhang's auteur biography; 'auteur biography' as it is not a full or exhaustive biography of Zhang the individual, but a condensed biography which includes those elements of his life that facilitate and justify the construction of his authorship. By the time that Zhang had begun to make films after the Red Trilogy, his auteur status was so well defined and established that it remained relatively unchanged until Hero, Zhang's eleventh feature film. This chapter investigates the construction of 
Zhang's status as an auteur which determined the reception of his films and created the discursive context that would effect the reception of Hero, years later. As Zhang's auteur biography is important to the reception of his films, it will be necessary to investigate the accounts of his preauteur life in how they have corroborated the characteristics of his authorship. This pre-auteur phase of his biography will be divided into two parts: the accounts of Zhang's experiences that occurred prior to his involvement with films, and his involvement with the Fifth Generation of Chinese filmmakers. After investigating these two pre-auteur parts, I will investigate the role that the 'Red Trilogy' has had in the discursive construction of his authorship. Investigating the articles, reviews, essays, and books that have been written about Zhang and his films reveals the 'recurring motifs' which, once established, predominated the reception and perception of his career and films: the first motif qualifies Zhang and his films as manifesting an aesthetic virtuosity; the second involves the interpretation that Zhang and his films exemplify an unequivocal cultural authenticity; the third is that Zhang and his films express subversive, anti-government politics. While investigating the emergence of Zhang's auteur status, I will be tracing these 'recurring motifs' of his authorship and how the discourse of the various phases of his life and career have been utilized to explicate these motifs. Each of these motifs have compounded and reinforced each other circumscribing the reading of Zhang's films. Awareness of these motifs and the way that they have determined the reception of Zhang's films provides an important foundation for understanding the way that Hero was later received and interpreted.

\section{The Construction of an Auteur.}

Over the last several decades auteur theory and authorship have been the subject of considerable debate. This thesis is an investigation of an artist being constructed as an auteur and the discursive consumption of that artist and his films in critical and academic circles. It is not an analysis of the validity of auteur theory. As such, it will take for granted certain assumptions of auteur theory and authorship ignoring the contested advantages and disadvantages of the various notions. The term 'auteur' refers to the filmmaker who, by virtue of control over his or her craft, produces a body of work which comprises several film texts; 'authorship' refers to that status as an auteur ascribed to a particular artist or, in this case, filmmaker (see Wartenberg and Curran 91). These film texts exhibit a quality, style, and theme that is unique to the individual filmmaker and consistent across their oeuvre. In such a way, the films are determined to be representative of the individual credited as director or 'author.' While such a problematic idea has been challenged as too naive to accurately describe the realities of film production in academia, identifying a film's 
auteur continues to be a significant component of the way film is discussed, especially in journalism ${ }^{6}$. For instance, the persistent importance of authorship is evidenced by Neil Smith's article for the BBC titled "Cannes Keeps Faith with Auteurism" in which he invoked Variety magazine's prediction that 2009 Cannes Film Festival would be the "biggest heavyweight auteur smackdown in recent years." What is of interest to this investigation is what effect this authorship discourse has had on the reading and interpretation of films made by those who are interpellated as auteurs.

Through international attention and recognition of his early films, Zhang has been acknowledged as an auteur in a manner akin to celebrity (See Lu, "Chinese Film" 121-5). Timothy Corrigan observed that "placed before, after, and outside a film text... today's auteurs are agents who, whether they wish it or not, are always on the verge of being self-consumed by their status as stars" (100). The concept of a being a star in Corrigan's analysis evokes Richard Dyer's notion that a star is a construction which consists of a "complex configuration of visual, verbal, and aural signs" (Dyer 34). Zhang, as auteur, is a constructed 'Zhang.' In 1972, Peter Wollen amended his auteur theory to differentiate the real individual from the constructed auteur: "Fuller or Hawks or Hitchcock, the directors, are quite separate from 'Fuller' or 'Hawks' or 'Hitchcock', the (auteur) structures named after them" (578). It is because of his filmic texts as well as extra-filmic texts that a historically specific Zhang Yimou has been interpellated into a mediated construction, or 'structure,' known as 'Zhang Yimou': the auteur. The relevant extra-filmic texts which contributed to the formation of the construction have been diverse and international. They have included his embodied presence at public screenings and international film festivals, interviews which promoted or investigated his films, honors and awards presented to him, stories told about him by others, reviews and analyses in newspapers and journals and books, etc. For instance, Sheldon Lu observed that "His ability to reap numerous awards at international film festivals has earned him nothing less that the title of a modern Chinese myth, the "myth of Zhang Yimou" ("Chinese Film" 125, see also Zhen 173). 'Myth,' here, appropriately correlates to the constructed quality of his auteur biography. ${ }^{7}$ All these texts contributed to the construction of the auteur status of Zhang Yimou by surrounding the auteur "always already in appropriation as the precondition, and not the postproduction of meaning" (Morris 122-23). This indicates a reciprocating loop: the auteur's

\footnotetext{
${ }^{6}$ For an historical overview of auteur debate see Hayward 31-8.

${ }^{7}$ The use of 'myth' in this thesis - here and in Chapter Two - is relatively straightforward. While there are complex and useful deconstructions of myths available - like Barthes who defined myths as, more or less, discursive structures that perpetuate ideals and ideologies (Mythologies) - here it simply refers to a sort of legend, or fictional story meant to explain some phenomenon. In this case the phenomenon is Zhang Yimou and his films.
} 
authorship defined and was defined by itself, the construction constructed itself. This also indicates that any 'real' Zhang Yimou has become shrouded and embedded within layers of construction so that any 'true' authenticity is impossible to derive.

Corrigan's argument was a response to John Caughie's concern that auteurs need to be considered in terms of how they are "constructed by and for commerce" (Corrigan 98, see also Caughie 2). Within the realm of commerce, Zhang's authorship has not been a willed selfconstruction but rather a 'brand name' which determined the discursive context for the consumption of each of the auteur's individual film texts (D'Lugo 118, Corrigan 97, see also Xu 28). Foucault has argued that within the function of the author, or 'author function', the auteur's name "permits one to group together a certain number of texts, define them, differentiate them from and contrast them to others" ("What is..." 107). Zhang's films are grouped together and each film is sold, not just as a film, but as a Zhang Yimou film. As an example of this proclivity, To Live (1994), which was produced and distributed after Zhang's authorship had been established, took advantage of that authorship for the distribution and sale of the film. To Live became Zhang Yimou's To Live where the film text's economic, critical, and academic existence was predicated upon its contextualization within the mythos of the auteur, Zhang Yimou. Zhang's films, such as To Live and even Hero, have been read through pre-existing codes that arose as a result of the discursive construction of Zhang's authorship - sold, studied, and interpreted first and foremost as a Zhang film, with other Zhang films. Corrigan argued: "to view a film as the product of an auteur means to read or to respond to it as an expressive organization that precedes and forecloses the historical fragmentations and subjective distortions that can take over the reception of even the most classically coded movie" (97).

There has been, and continues to be, a tendency of western critics and academics which accompanies the practice of ascribing authorship to an individual and to a film. This tendency, an auto-reading propensity, positions a film to be automatically read based on the conditions and characteristics of the authorship which has been previously constructed by discourse. Foucault explained that identifying an author "is a speech that must be received in a certain mode and that, in a given culture, must receive a certain status" (107). That speech, and the way in which it 'must' be received functions "to circumscribe the reception and reading of a text. The text is already to be received in a particular way once the author of that text is announced" (Projansky and Ono 266-7). This suggests a biased hermeneutics prejudiced by the auteur discourse that surrounds and also precedes the text. The interpretations and representations read into the film text are directly correlated to the way in which the auteur is constructed. Simultaneous to the formation of this 
determining discourse, the authorship discourse is also at work dictating a determination of the 'biography' of the auteur in a reciprocating explication.

Foucault wrote that "the author provides the basis for explaining not only the presence of certain events in a work but also their transformations, distortions, and diverse modifications (through his biography, the determinations of his individual perspective, the analysis of his social position, and the revelation of his basic design)" (111). Once identified, auteur discourse accumulates biographical details to help explain characteristics and qualities of the author's work. The biographical information becomes an integral component to the construction of the auteur and how that dictates the way the films are read. It is important to acknowledge that investigating the biography of Zhang the auteur does not necessitate any authentication of the details, whether Zhang was born in 1950 or 1951, for instance, does not matter. It is not the history of Zhang, but of 'Zhang' that is relevant. What does matter is those details of his biography that appeared and reappeared in discussion of his film as a way of explaining his films or justifying certain qualities of his auteur status.

Zhang has been known first and foremost as a director. That is to say, the myth that has constituted Zhang's authorship identity had its genesis in the films that he created - those primary texts of the constructed auteur - and once he was initiated as an auteur, extra-filmic readings, biographical accounts, and texts emerged to reinforce his authorship and circumscribe his authorship identity with various characteristics. Zhang's 'pre-auteur' history has often been included ex post facto in the constitution of his auteur status. Accounts of his past have been variously invoked by critics and academics to facilitate the explanation and construction of his auteur present. An important function of Zhang's pre-auteur history has manifested as a way to divine a connection between the auteur's personal life and his artistic creation, to craft an explanation for the message, motivation, or meaning of his films.

As the biographical accounts of Zhang's origin effected the construction of his auteur status - thus creating the discourse through which his films have been interpreted, read, and understood it is useful to review some of the phases of Zhang's auteur biography to understand how they have discursively contributed to this construction and its related readings. It will also be necessary to trace the three recurring motifs as they were justified and supported by attributes that make up those phases of Zhang's auteur biography. The details of Zhang's auteur biography were endowed with relevance as they have been cited, analyzed, referenced, and recalled in the analytical discourse of Zhang's films and authorship. In this way, characteristics of Zhang's films have simultaneously justified and were justified by biographical details. 


\section{Zhang's 'Pre-Auteur' life.}

The most important function of the pre-auteur phase of Zhang's auteur biography has been to align Zhang with the Chinese peasant while also establishing a peasant/government binary that became important to the discursive reception of Hero explained in the next chapter. That binary has served to qualify the Chinese peasant as living in opposition to the Chinese government as Western perception has operated under the assumption that the plight of the Chinese peasant is centered on being victims of Chinese Communist Party oppression. Like other dynamics of the construction of Zhang's authorship, the historical reality of the peasants' plight has been inconsequential to the constructed relationship established by discourse and integral to Zhang as auteur. Aligned with the peasant, Zhang's authorship has simultaneously reinforced his cultural authenticity and political subversiveness. His interest in, and proficiency with, photography during his peasant experiences has functioned to 'explain' his aesthetic virtuosity.

Zhang Yimou has been associated with the Chinese peasant since the beginning of his career. Tony Rayns observed in 1989 that the Fifth Generation's early films, including Zhang's first film, demonstrated those directors" "predilection for rural subjects" that reflected "their own pasts in the countryside" (24). Around the release of Hero, and not long after the release, there were several writers who wrote accounts that specifically addressed Zhang's personal predilection for the countryside. These accounts are emblematic of the discourse connecting Zhang to the Chinese peasant and reflect the culmination of how Zhang's authorship has been constructed to manifest a peasant alignment leading up to the reception of Hero.

In the late 70s, Chen Kaige - Zhang's colleague in the Beijing Film Academy and fellow Fifth Generation filmmaker - wrote a writing sample entitled Man of Qin for admission to the Beijing Film Academy (Zhen 21). This piece was not translated or available in English until Ni Zhen's Memoirs of the Beijing Film Academy was published in 2002. While it might have been received differently in China, when it was translated for English speakers it contributed to the discourse of Zhang's authorship reflecting and reifying his peasant attributes in time for Hero's wide American release. In the English translation, Zhang Yimou is clearly presented as the titular 'man of Qin' romantically constructed as intimately connected with China's history, culture, and the experiences of its common people. "If you walk to the west," Chen wrote, "you come to the glories of Chang'an. Zhang Yimou came from there. He didn't want to make a name for himself, but he had a sincere and honest ambition. That was to work for art, which is what his name means, not to work for material things" (qtd. in Zhen 21). Chen elaborated that Zhang was from the land of Qin, 
the resting place of emperors and empresses, a place where scenery and legends of China's history inspire. "But his greatest concern," Chen concluded, "is the joy and woe of the common people, among whom he includes himself" (qtd. in Zhen 21-2).

Chen's piece demonstrates the way that Zhang's biography had discursively reinforced the notion that Zhang embodied an affinity with the 'common people' of China. His films and auteur status has thereby been interpellated as embodying an authenticity substantiated by peasant qualities. Discussing Zhang's involvement with the 2008 Olympics, the screenwriter Wang Bin recalled $J u$ Dou, a film that Zhang directed earlier in his career. In this explanation, Wang revealed how Zhang's auteur construction was synonymously tied to the representation of China, with a particular emphasis on the 'common people.' While Wang Bin is Chinese, his interview was a part of an Olympics 'behind the scenes' video available to New York Times' online American readership. Even though Wang's comments were expressed years after Hero's release, it shows that when talking or writing about Zhang's early films it has been a regular practice to promote the peasant alignment of Zhang's auteur construction. His comments ultimately echoed and reinforced Zhang's established authorship.

Zhang Yimou is a miracle. Westerners knew little about China until Zhang Yimou shot Ju Dou... Chinese culture is still rooted in the countryside. If you don't know the Chinese peasant, you don't know China. Zhang Yimou has a strong connection to the countryside and the earth. In fact, the very first time I met him... he was honest and simple, like a farmer. (Behind the Scenes, emphasis added)

According to Wang, the miracle of Zhang Yimou was how he utilized his "connection to the countryside" and provided an authentic representation of China, through films like $J u$ Dou. Importantly, Wang's comments also indicate how 'China,' as related to Zhang's early films, refered to the people not the nation-state or government.

Similar to Wang Bin's description was Vincent Brook's auteur study of Zhang Yimou published in 2003. Brook's analysis offers an example of how the pre-auteur phase of Zhang's auteur biography has been directly applied to understanding his films, while information about the pre-auteur phase was also directly extracted from those films. Adapting and appropriating Jenny Lau, Brook analysed how Ju Dou can be read as autobiographical, presenting the viewer with subtle insight into Zhang's personal and political experiences and attributes - to which we might add his personal politics. Ju Dou is a film that portrays a woman, Ju Dou, who is the purchased wife of an abusive and impotent dye mill owner, Jinshan. The film is set in a rural textile dying mill and the narrative centers on the experiences of the mill workers. Ju Dou has an affair with Tianqing, 
Jinshan's adoptive nephew. Throughout the film, Ju Dou and Tianqing are oppressed by the abusive and controlling Jinshan. Even after Jinshan dies, Ju Dou and Tianqing are not allowed to live as they desire as they struggle to appease cultural expectations and hide their illicit affair. By the end of the film, Tianqing has been murdered by their child and Ju Dou kills herself by burning the mill around her. Brook argued that "embedded in this 'projected world,' no less than the historical reader, is the text's biographical author" (22). Brook interpreted Ju Dou's setting in a textile mill as representing Zhang Yimou's experience during the Cultural Revolution where he spent three years working on a farm and later spent seven years at a spinning mill (Brook 25; see also Gateward xiii). Brook also read Ju Dou's narrative as emblematic of Zhang's struggle against government authorities, representing his experience in the Cultural Revolution. "Both Tianqing and Zhang, like the Chinese people as a whole, seem ever caught in a vice between the repressive regimes of old and new, past and present" (Brook 27). Zhang's experience with the Cultural Revolution has served to justify his subversive position against the Chinese authorities, and was often read into his films as the reason they have a subversive message (see Xu 33). Zhang's childhood as a member of a 'bad background' family reinforced this subversive justification. Zhang has explained that being listed among the 'Black Five Categories' meant that they "were severely discriminated against ... you were allowed to do certain things and not allowed to do other things" (qtd. in Cardullo 127-8; see also Gateward viii). Having been the indirect target of governmental prejudice both in the punishment of his father's transgression against the state and also as a youth victim of the cultural revolution has ensured Zhang's discursive eligibility as an authentic peasant and provided explanation as to why he would be anti-government.

Borne out of, and tied directly to, Zhang's cultural authenticity and his subversive politics, is the third motif which characterized Zhang as visually virtuosic. While at the spinning mill during the Cultural Revolution, Zhang developed an interest in photography and began saving for a camera. The story has since circulated that Yimou began selling his blood regularly to supplement his income. Eventually he saved enough and he bought a camera (Brook 25; Gateward viii, xiii; Chow 162). Thus the origins of his visuality has been rooted in the countryside and his experience as a Chinese peasant. When the Beijing Film Academy reopened following the end of the Cultural Revolution, Zhang used his photography skills to apply. He joined thousands of other 'peasants' who saw the Academy as an opportunity to change their circumstances, but Zhang's application was rejected because he was too old. So, he appealed directly to the Minister of Culture using his photography portfolio. He was then accepted into cinematographic training (see Gateward viii, xiii). These details of Zhang's life, previous to his involvement with film, have become utilized and 
proliferated by critics and academics once he started directing films. Often his background in photography, an art dependent on visuality, has been cited in the discourse of his authorship with the implication that it aptly 'explains' the visuality that his films have often been recognized for.

\section{Zhang and the Fifth Generation.}

Upon graduating from the Beijing Film Academy, Zhang became a part of the Fifth Generation of Chinese filmmakers along with fellow graduates such as Chen Kaige and Tian Zhuangzhuang. Writing about Zhang's involvement with the Fifth Generation perpetuated and reinforced the three motifs of his authorship. The Fifth Generation refers to the first group of filmmakers that graduated from the Beijing Film Academy after it reopened following the cultural revolution.

Going under the moniker of the 'Fifth Generation' served an important function delineating their group from the filmmakers that were of the Third and Fourth Generation (Brook 22-3). When the Fifth Generation started making films, films from the Third Generation still dominated the market. Third and Fourth Generation 'socialist realist' films were criticized by the Fifth Generation as "dreadful," as lacking substance and feeling, and as exhibiting "falseness" (Chen and Haque 64-6). For instance, Zhang was angered when he saw Xie Jin's Flowers Beneath the High Mountains (1984). What angered him was that the film manipulated "audience's emotions by the over-dramatic patriotic story" (Chen and Haque 66). This reactionary attitude would characterize the films of the Fifth Generation, consequently it also contributed to Zhang's discursive construction, becoming an important characteristic of his authorship. Setting themselves apart from the previous generations, Zhang and his colleagues set out to make films that "do not automatically toe the socialist line," insisting that their films would "not spew out party propaganda" (Cardullo 111, see also Chen and Haque 63).

In order to delineate themselves from the third and fourth generations, the Fifth Generation's filmmaking style exhibited unprecedented experimentation with formal strategies. While still at the Academy the Fifth Generation students were influenced by foreign films and theorists. Following the cultural revolution, the Chinese government relaxed many of their policies regarding international cultural exchange. As a result, Zhang Yimou and his colleagues had tremendous access to films, books and essays created by European filmmakers and writers which inspired the experimentations of the young filmmakers (Chen and Haque 68-9). Another significant factor in the Fifth Generation's experimental approach to filmmaking was the discordant shift in the Chinese film industry that was underway when the film students graduated and began looking for jobs. 
While many of the studios in China had transitioned to production and distribution strategies dictated by a market-driven film economy, a few studios remained aloof from the pressures of making a profit. As a result, some of the new graduates were able to take advantage of these studios that had not yet made the transition. Zhang Yimou was one of these students. He began work at Guangxi Film Studio which was still largely government funded. This allowed for the production of art oriented films that did not need to make back their investment. Working as a cinematographer, Zhang Yimou was soon joined by his fellow film academy graduate, director Chen Kaige, and together they made Yellow Earth (1984), one of the Fifth Generation's premiere films. The enthusiastic reception of this non-traditional film at the Hong Kong Film Festival led Tony Rayns to declare 12 April 1985, the date that Yellow Earth inaugurated "New Chinese Cinema" (2).

Zhang has since been identified as the most "prolific, versatile and significant" (Farquhar "Zhang") of all the Fifth Generation filmmakers, on account of his dominant international profile. Zhang's significance among the Fifth Generation was a result of his award-winning participation in 'new wave' films as cinematographer and even actor (see Lu, “Zhang” 412). His contributions to these 'new wave' films was so significant that many have attributed the success and innovation of the Fifth Generation's early films on Zhang's camera work (see Brook 24, Farquhar “Zhang”). His involvement, often pivotal, in the 'New Chinese Cinema' meant that qualities of these films became co-opted into Zhang's own auteur construction once he began to direct films himself. So, when David Neo notes that "the Fifth Generation filmmakers have been applauded for their hauntingly beautiful, culturally rich and multi-layered cinematographical language," it is not hard, given the discourse of Zhang's authorship, to replace Fifth Generation with Zhang Yimou without compromising the statement's discursive validity.

In spite of Yellow Earth's enthusiastic reception in Hong Kong, the Chinese government deemed it too negative in its portrayal of Chinese peasants (Zhang X. Chinese Modernism 361). Government film censors determined that the film's representation of China's people had unacceptably deviated from the status quo of previous socialist realist films. The result was that the government chose to disallow, or ban, it from further participation in other international festivals (Chen and Haque 71). The government censors choosing to disallow this film contributed to the development of the Fifth Generation filmmakers' infamous reputation of being politically subversive. They were politically subversive because they were known to repeatedly upset the Chinese film censors. This reputation meant that New Chinese Cinema was often characterized as 
politically antigovernment, whether or not Fifth Generation filmmakers were even trying to be political. With regards to style of Yellow Earth, Esther Yau observed that

the tyranny of (socialist) signifiers and their signifieds is contested in this approach in which classical Chinese painting's representation of nature is deployed to create an appearance of a 'zero' political coding. Indeed, the film's political discourse has little to do with official socialism; rather, it begins with a radical departure from the (imported) mainstream style and (opportunist) priorities of narrative film-making in China. One may even suggest that Yellow Earth is an 'avant-gardist' attempt by young Chinese film-makers taking cover under the abstractionist ambiguities of classical Chinese painting. (24)

The language Yau used is rooted in an investigation of Yellow Earth's politics. Through its discursive position, the film is interpreted as necessarily representing politics. Even if the film does not explicitly address politics, it has been read as though it addresses it implicitly. Under the determining discourse of these films, it has been nearly impossible to interpret them absent of any political meaning. Tony Rayns has argued that the Fifth Generation "has to be read through their general sense of political disillusionment" (9). This determination has problematically conflated all of the Fifth Generation filmmakers in their complex differences and figured them all in some relationship to the political. It is also problematic because it suggested that they are all read through a specific political position, as politically disillusioned (see also Zhang X., "Cinema" 135). When Zhang began to make his own films in the late $80 \mathrm{~s}$, this way of reading films of the Fifth Generation followed him and dictated that his films were also read politically.

Rather than reading Zhang's biographic history as a success story which might valorize his struggle through difficult circumstances, his history has justified reading his films as highly political and potently antigovernment. This reading persisted in spite of his own protests that he was "not interested in politics" (Jiao 11). Bill Nichols has provided some insight into the tendency to read auteurs as resistant or subversive. He said that

a frequent tenet of auteur criticism is that a tension exists between the artist's vision and the means at his disposal for realizing it: studio pressure, genre conventions, star demands, story requirements. These constraints are also seen as a source of strength, imposing discipline and prompting cunning subversions. (306)

The way in which Zhang's history has been invoked is characteristic of this tendency of auteur approach to identify auteurs as 'rebels' (Staiger 35). The theme of struggle read and invoked throughout his biography pits Zhang as a 'common' David against the oppressive Goliath of the 
Chinese Government - an exciting and popular mythology. His history, as constructed in the discourse of his auteur status, inspired the common assumption that Zhang has had a tense, "lovehate" relationship with the Chinese government (see Cardullo 128). The subversive political allegories that have been read into each of his films were interpreted as a 'natural' result of, and expected response to, Zhang's historical experiences.

Zhang's auteur biography, then, 'preempted' the reception of his movies and participated in influencing how they were interpreted (Corrigan 100). Each element perpetuated and fueled the other in a complex dialectic that circumscribed and prescribed the Zhang-as-auteur frame of reference. This is not to say that there was not a subversive voice in his films, nor does this mean that he does not have a reason to be antigovernment. It would be easy to justify him as antigovernment, as many have, on account of his family's position in the margins of 'acceptability' and being a victim of the cultural revolution. But, the presiding tendency in the discourse of Zhang's authorship to read him as politically subversive has foreclosed the reality of Zhang's 'actual' relationship to the Chinese government, and has cast him as having reason to be subversive - whether he was or not. In this context, Zhang's first three films, his 'Red Trilogy,' was read as a realization of perceived political angst against the Chinese government explained by his supposed victimization - he has been a peasant protagonist struggling against the antagonizing communist party. This has reinforced the binary opposition at the center of the auteur status of Zhang Yimou.

\section{Zhang's Red Trilogy.}

By the late 1980s, Zhang had moved to Xi'an Studios. Xi' an Studios had joined most of the other studios in China in the concern to recuperate costs of production in sales at the box office (see Lee, "Into/Out," Lau, "Hero"). When Zhang moved from cinematographer to director he tried to differentiate himself from the other Fifth Generation directors. At that time, critics accused Fifth Generation filmmakers of possessing 'narrative impotence,' the inability to construct narratives that could be compelling for mainstream audiences. As a result, Zhang determined to craft an "art film with box-office potency" (Zhu 112-3); a "bastard film" that would incorporate the formal experimentation of New Chinese Cinema with traditional and popular narratives. Red Sorghum, Ju Dou, and Raise the Red Lantern would be characterized by this dual ambition, an approach that set Zhang apart from his contemporaries. These are the three films that became known as the 'Red Trilogy' and were the genesis of Zhang's international reputation establishing his "signature as a filmmaker in a storytelling mode dominated by visual display" (Farquhar, "Zhang"; see also Chow, Primitive 143). The trilogy was the primary site of inscribing auteur status to Zhang as the use of 
'signature' and 'trademarks' indicates that there has been an observed repetition throughout the auteur's various works (see Staiger 43).

With international acclaim for his cinematography in early films of the Fifth Generation, it is not surprising that the visuality of his early films were considered virtuosic. When Red Sorghum screened at international festivals, critics applauded the aesthetic splendor that it presented. Desson Howe wrote for the Washington Post that Zhang's “images intoxicate your eyes... you get so drunk on his artistic bouquet, you worry about driving home... if Yimou's debut were any better, he'd have to be tested for artistic steroids." Roger Ebert contributed his own praise for the aesthetics, "the cinematography in Red Sorghum has no desire to be subtle, or muted; it wants to splash its passionate colors all over the screen with abandon, and the sheer visual impact of the film is voluptuous" ("Red Sorghum"). Even while criticizing the film for falling short of its potential and deteriorating into 'propaganda,' Hal Hinson acknowledged the "sensuous command that director Zhang Yimou has of his medium." While praising his cinematography, Vincent Canby and Manavendra Thakur each wrote of how Zhang's visual presentation of narrative was connected to peasants, servants, and the earth. Canby, writing for New York Times, described it as "a handsomely produced, finally lugubrious piece of exotica about picturesque peasants." Furthermore, Thakur from The Tech wrote of the film's

breathtaking color cinematography... Not only do the narrative and actors stay close to the earth, but the wine-and much of the other imagery-has rich, reddish color that immediately gives the film a life-blood vitality. These images are bold, rich, and striking, and one virtually can get intoxicated from them, feeling a closeness to the winery servants as well as the earth itself as the men at the winery go about their tasks and sing prayers in praise of their wine.

While not directly declaring Zhang as 'authentic' per se, these last reviews took for granted the authority of the film, and by extension the film's author, to bring us 'close to the earth.' This is similar language to that which was used to describe other aspects of his life, such as when Chen Kaige wrote of Zhang's common-people quality or when Wang Bin linked Zhang to the Chinese peasant farmer (Chen in Zhen 21-2; Wang in Behind). Connecting these qualities directly to the visuality of the film, as Manavendra has, Zhang's visuality has reinforced his cultural authenticity.

While there have been many components of the aesthetics of his films that are complex and noteworthy, the liberal use of the color red serves as a suitable example of how Zhang's visuality has been discursively tied to his subversive politics. In the films, Zhang's manipulation of the color against its traditional signification reconfigures its meaning. Instead of being joyous and 
celebratory as the color traditionally symbolizes in Chinese culture, it subverts that traditional significance. Red is so prominent and pervasive in the films that characters within the colorful surrounding often appear less significant than the red color that oppresses, and threatens to destroy them. In $J u$ Dou, for instance, the textile mill that provides the setting is full of vats of red dye and newly dyed red cloth, dripping as they hang to dry in the sun. Each major action by the characters is surrounded by red, as though the color motivates and influences the characters' decisions and actions. Ju Dou and Tianqing's love affair begins set amongst the deep vibrant red hues of the freshly colored cloth in the dye mill. The red represents the new passion that was once oppressed and now is realized in unbridled expression. But at the end of the film, red manifests as ultimately oppressive and destructive as the color smothers the inhabitants of the home and domesticity. The deaths of Jinshan and Tianqing occur as they are consumed by the red dye, and Ju Dou immolates herself with red fire while surrounded by red fabric and dye.

Because of the threat to the characters, the color red has often been interpreted as integral to the political subversion in the films of Zhang Yimou. In $J u$ Dou "a rebellious use of color in defiance of the traditional code further accentuates its theme" (Lau, "Ju Dou” 141). The love, hope, and sexuality of a more conventional red signification are replaced by indignation, violence, and outmoded traditions of filial piety that oppresses the inhabitants who long for independence. $J u$ Dou's finale punctuates the irony of the film as the title character is immolated by the color that once offered the hope of desire, passion, and freedom. The 'simple' stories of his narratives, are recoded through the aesthetics "with a special ironic power" (Kong 123-4).

Similar to Ju Dou, Red Sorghum's use of the color red has been interpreted as subverting its traditional signification. Red Sorghum tells the story of a bride, Jiu'er, who is betrothed to the leprous owner of a distillery, Li Datou. The distillery makes a sorghum wine, which has a deep red color. The film begins as the bride is escorted in a red sedan chair through sorghum fields that are red with autumn maturity. Jenny Lau points out that red has a specific significance in Chinese art, it is a color for "important rituals and ceremonies such as marriages, birthday celebrations, and so forth" (“Ju Dou" 141). In Red Sorghum, the joyous and celebratory red of the sedan chair contradicts the reality of the bride's impending fate as the arranged wife of an aged leprous man. In this juxtaposition, the exuberance of the festive color is replaced by an inescapable futility. Then there is an illicit affair between Jiu'er and a bandit consummated in the red sorghum fields. After Li Datou is killed, the bandit and Jiu'er run the winery, and soon, Jiu'er bears the bandit's son. The success represented by the red wine, and the passion of the red sorghum fields turns to destruction by the last scene of the film. In Red Sorghum's final shot, the bandit and his son stand over Jiu'er's 
now lifeless body while surrounded by the red of the sorghum and the spilt wine. That last shot is red, heroic, and tragic all at the same time, simultaneously ironic and ambivalent. Where the pervasive color might otherwise inspire passion, in Zhang's film it instead suffocates and imprisons those that are passionate. Using red this way has been, in part, why Haili Kong has called Zhang's aesthetics his "subversive lens" (Kong 115).

\section{Beyond Authorship?}

Through the discourse of the Red Trilogy and Zhang's auteur biography, Zhang's authorship and films have been constructed as manifesting the recurring motifs - embodying the qualities of being visually virtuosic, culturally authentic, and politically subversive. This constructed authorship has perpetuated a persistent reading of Zhang's films and biography that has proven to be an important framework through which his career has been read. It also created expectations that have predetermined the reception of his films. However, there are problems that arise when the constructed authorship of Zhang Yimou is put to scrutiny. Foucault wrote that "even when an individual has been accepted as an author, we must still ask whether everything that he wrote, said, or left behind is part of his work" (103). This query brings to mind one of the fundamental faults of the construction of Zhang's authorship. What is included, and what is excluded, in the oeuvre that constitutes Zhang's auteur status? Looking at the films and texts cited by critics and academics discussing Zhang's authorship, it is clear that there are some texts which have not been included in the canon. Films like Operation Cougar (1989) and Keep Cool (1997) have rarely been included in discussions of Zhang's filmmaking career. Operation Cougar was Zhang's second film, and yet it remains 'lost' in the midst of the release of his auteur defining Red Trilogy. If these films were included by writers, they were often casually discarded as unsuccessful attempts at urban drama. While it may be true that they were unsuccessful - no copies of either of them have been sold in the West mainstream market, and as of this writing there does not appear to be a copy in existence of either of these films with English subtitles - it is unclear why these films have not been included in Zhang's authorship.

In addition to full length feature films, Zhang has been involved in a number of other creative ventures since he began making films. For instance, he contributed a short film to Lumière and Company (1995), a collection of short films made by internationally renowned directors who utilized a cinematograph in celebration of the 100 year anniversary of the Lumière brothers' invention of the same device. Zhang's short in this collection features a Chinese man in traditional Peking opera costume dancing on China's Great Wall. Half-way through the clip, the man tears off 
the opera costume to reveal contemporary rock clothes as he then proceeds to jam on an electric guitar. There is also the erotic short, "En Regardant le Film," his contribution in a collection of shorts titled To Each His Own Cinema (2007). "En Regardant le Film" is Zhang's tribute to the sensual experience of cinema. It portrays an individual alone in a cinema surrounded by the empty red seats of the theater as he 'enjoys' a film. While some of these extra-auteur texts would reinforce many aspects of his already constructed authorship, many of them would challenge it. The Lumière short which explores icons and representations of Chinese culture and identity challenges authenticity by portraying culture as a facade - as a costume that can be worn, changed, and discarded. "En Regardant" is a representation of embodied pleasures of film experience and emphasizes that visual pleasures are merely part of the cinematic experience. The predominant red color palette resembles the Red Trilogy, but the use in this short film is straight-forwardly traditional, representing the passion that the viewing pleasure potentially provides, no subversive ironic twist. This short film is more suitable for a phenomenological analysis and even resists interpretation through national or other paradigms as there are no other markers in the film that would facilitate such a reading. The fascist framework implies that Hero is evidence that Zhang has become a 'sell-out' because with Hero he was only interested in box office success rather than politically subversive messages. Operation Cougar, predating Hero by more than ten years, was a genre film intended for box office success with a frivolity that threatens to disrupt the perception that Zhang's early films were a profound expression and exploration of subversive politics. Furthermore, there is evidence that even Red Sorghum was guilty of being a film intended for mere box office success. One of the three promises that Zhang made to the head of Xi' an studios was that the film would generate "commercial box-office success" (see Jiao 10).

Consideration of these numerous 'forgotten' texts raises suspicion that Zhang's authorship is not as coherent as the discourse might suppose and challenges the foundational characteristics upon which that authorship has been constructed. It appears that these texts transgress the established auteur status and that is why they have not been included. The issues raised here about the politics of auteur discourse are beyond the scope of the current project. As this thesis is interested in identifying and analyzing the fascist framework, not auteur theories, it is sufficient to simply note that there are problems foregrounded by the consideration of these lost texts. These problems reveal fractures in the construction of Zhang's authorship which allow for a reconsideration of the way that Hero's reception was interpreted and constructed as a culmination of a straightforward career trajectory. 
Before exploring a reconsideration of his career and films, there is another discourse that has had a determining function on the reception of Zhang's films. When analyzing Zhang's authorship construction, it is difficult to separate his authorship from his constructed relationship to the Chinese nation-state. His discursive association with China and the discursive tendency to read his films as a product of Chinese national cinema needs to be investigated and examined. Both national cinema as well as authorship can be said to have played nearly equal co-determining roles in the reading of Zhang's films. Comprehending the role of these two discourses is important to understanding the emergence of the break in Zhang's perceived authorship when he directed Hero. While this chapter has investigated the construction of authorship, the next chapter will focus on the national cinema side of the discourse of Zhang Yimou, auteur of Chinese national cinema. 


\section{Chapter 2:}

\section{Hero's Reception and the Fascist Framework.}

For two weekends in late August and early September 2004, a film from mainland China held the top grossing position in the American box office. Zhang Yimou's first martial arts epic film, Hero, opened in more cinemas across the United States than any other film from China - an accomplishment it still holds exclusively to this day ${ }^{8}$. This film caught the attention of prominent American film critic Roger Ebert who gave the film three and a half out of four stars concluding that "Zhang Yimou, whose Raise the Red Lantern was so beautiful, once again creates a visual poem of extraordinary beauty" ("Hero").

Many critics praised the film's aesthetics, often comparing it, like Ebert did, to Zhang's early films. Box office figures indicate that the film achieved notable success among American audiences. In spite of this success and praise, the fascist framework and its associated controversy became a prominent way in which the film's perceived message has been interpreted. Months before Hero's American theatrical release, Evans Chan wrote his critique of the film which has since been widely circulated, referenced, and quoted in the discourse surrounding Hero's reception in the West. As to Chan's opinion of the film, the title of his essay could not be clearer: "Zhang Yimou's Hero and the Temptations of Fascism." Indeed, not only did Chan rebuke the politics of the film but in that rebuke, he connected his criticism directly to the film's creator; it is not just Hero, but Zhang Yimou's Hero which was condemnable on account of its promotion of authoritarian governance. Chan's essay has been a central text for the 'fascist framework' or the 'fascist argument'.

Within the fascist framework, Hero has been discursively read as a 'shift' or a 'break' in Zhang's authorial style. This 'shift' highlights the peasant/government binary which has been central to the fascist framework. This binary has contributed to the determination and interpretation of Zhang's relationship to the Chinese nation-state, which in turn has determined whether Zhang's films have been read as pro-national or anti-national. There have been other binaries that dictated the interpretation of Zhang's relationship to China, with various dynamics involved. For instance, within Rey Chow's Primitive Passions, Chow interrogated the criticism of Zhang that his films

\footnotetext{
${ }^{8}$ Kung Fu Hustle eventually screened in more cinemas but not at opening, and it never earned more at the box office than Hero did.
} 
were self-orientalizing (see 166-72; also Lu, "Historical" 7-10). Chow's analysis demonstrates that, previous to Hero, an important binary in the reception of Zhang's films was an authentic/inauthentic binary based on Zhang's perceived alignment with a Western perspective of what Chinese culture was. The reception of his early films in the West was framed around the perception that those films were authentic, presenting to the West a Chinese national identity through the presentation of cultural artifacts and rituals. But to audiences in China, Zhang's films were self-orientalizing and inauthentic, implicitly read as a perversion of Chinese national identity as those films presented a view of China aligned with the Western gaze. While this and other binaries where important to the reception of Zhang's early films, the fascist framework mostly ignored this and other binaries and has discursively relied on its own implicit binary. The fascist framework's binary read pro-national and anti-national as determined by whether Zhang's films were either representative of the Chinese peasants, or promoting the government. This peasant/government binary juxtaposed with Zhang's authorship reconfigured the recurring motifs so that they justified the fascist argument. In this framework, subversive means to be pro-people while submissive means to be pro-government. This is how Zhang, once favored and well liked by critics at festivals, was considered as no longer artistically, or politically relevant with the release of Hero.

In the previous chapter, I traced the recurring motifs of Zhang's authorship across periods of Zhang's auteur biography. Here I will investigate Zhang's relationship to the Chinese nation-state which, through the discourse of the fascist argument and the implicit reconfiguration of the determining binary, has reinterpreted those motifs as constituting the alleged shift aligning Zhang and his film with the government, not the people. Zhang's aesthetic virtuosity once seen to represent a unique Chinese art, with Hero became commercial and propagandistic. These aesthetics supported a cultural authenticity which has been reoriented from an alignment with the common Chinese peasant to a position of servitude with the Communist national bureaucracy. Ultimately, this alignment reinforced the last motif which also shifted and which summarizes the fascist argument; once a director of subversive, anti-government films Zhang Yimou was perceived as endorsing submissive pro-government ideology. These motifs and their perceptive shifts are evidence that the fascist argument arose when Hero met the determining auto-positioning framework of Zhang's constructed auteur status and the discursive relationship to the Chinese nation-state. Before addressing these motifs it is first necessary to explore the fascist argument and the issue of national cinema paradigms. 


\section{Hero as Fascist.}

Evans Chan was not the first nor the last to denounce Zhang's politics. It took Hero a year and a half before it was available in general theatrical release in America. In that year and a half it screened around the world at various film festivals and select screenings. From its initial premiere in China, criticisms about its perceived politics had already incited debate. As the film's release spread, so too did those criticisms and the accompanying controversy. On the 2nd of January, 2003, not long after its initial premiere in China, Joseph Kahn wrote in The New York Times a review of the film titled "An Emperor is Reinvented, A Director is Criticized." The film had not yet been screened in any Western market ${ }^{9}$ and Kahn described the already growing controversy of the film's politics: "it has infuriated some Chinese critics, who have panned Mr. Zhang's plot for promoting a philosophy of servitude.” In London, Geoffrey MacNab wrote in anticipation of Hero's screening at the Berlin Film Festival. He observed that "Zhang Yimou's martial-arts epic Hero is causing the director a world of trouble." The reason for Zhang's 'trouble' in MacNab's review was the same thing that infuriated the critics in Kahn's article. These described the beginning of the controversy that later was centered on the allegation that Hero promoted fascism.

The use of the term 'fascism' not only qualified the type of politics interpreted in the film, the way it was used by the fascist framework explicitly refered to a particular relationship with the state. Of paramount importance in investigating the fascist controversy is understanding this implied relationship and why 'fascism' was used. While it may be that Chan used the term to incite emotional response from the reader he also usefully qualified why it was appropriate for his analysis. He insisted that "the impulse behind the film can be called fascist - it promotes a personality cult that claims oneness with the progression of the national destiny, and which inspires willful, bloody sacrifices" (18). In Chan's own qualification of how the film promoted fascism, he discussed the conclusion of the film's narrative as the primary basis for the whole argument. Emphasis on Nameless's death, under the auspices of an idyllic quest for national unity and peace, provided the foundation by which the film was read as fascist. Furthermore, the "oneness with the progression of the national destiny" reinforced the fascist allegation which has implied an alignment with the national at the expense, or sacrifice, of any individual ambition.

There have been other writers who promoted and perpetuated the fascist framework's reading of the film. After Chan's critique and just before the theatrical release of Hero in America, J. Hoberman echoed Chan and wrote that the film is "redolent of fascinatin' fascism." This

\footnotetext{
${ }^{9}$ Hero's first Western screening was at a film festival in California on 14 January 2003 and was distributed to various other festivals and smaller Western markets in Europe leading up to its wide theatrical release in America, over one year later: 27 August 2004. (imdb.com)
} 
comment was an allusion to Susan Sontag’s 1975 essay "Fascinating Fascism" which was an analysis of the work of Leni Riefenstahl, a German filmmaker responsible for propagandistic films which promoted Hitler's Nazi party - such as Triumph of the Will (1935). It is difficult to determine whether Hoberman's article was influenced directly by Chan's essay even though Chan's essay predated Hoberman's article by several months. Nevertheless the similarities of the two writer's sentiments place the two articles into the same framework. Hoberman's reference to Leni Riefenstahl reinforced Chan's most indicting allegation when Chan wrote that "Zhang Yimou is now the closest thing to being the Leni Riefenstahl of China" (22). Months later, psychiatrist Alan Stone weighed in on the matter. Citing Chan's essay, Stone promoted the idea that Zhang's new film indicated a shift in the director's authorial style. From the perspective of the fascist framework, Stone concluded his analysis of the film expressing the hope that in the future Zhang "will rediscover the artistic values that made him one of the world's most respected filmmakers" (16). As evidence of the persistence of the fascist framework, Xan Brooks perpetuated this indictment in 2010, over seven years after Hero's initial release. When discussing the similarities between Zhang Yimou and Danny Boyle - both filmmakers called upon to direct the opening and closing ceremonies of the Olympics hosted by their respective countries - Brooks identified both Zhang and Boyle with Leni Riefenstahl. These are a few of many writers who discursively supported the fascist argument and have implicated Hero with similar terms. What becomes clear is that these allegations were a direct commentary on Zhang Yimou's perceived relationship to the Chinese nation-state. These writer's declaration that he was 'now' fascist or 'now' a Leni Riefenstahl figure suggests that there was a shift in that perceived relationship with the state with demarcated characteristics as pre-Hero and post-Hero. The correlation of Zhang's relationship to the state with the perceived shift in his authorial style was made very clear when Chan summarized Zhang's career leading up to Hero arguing that "Zhang became the most engaging, fiercely critical storyteller about the throttling hold of gerontocracy until, alas, the tightening grip of the state finally caught up with him" (18). According to this critical paradigm, the once subversive filmmaker succumbed to the temptations of fascism and became, with the release of Hero, submissive to the Communist government and her censors. The controversy of Hero's alleged political persuasion foregrounds Zhang's constructed authorship and his relationship to the nation-state, especially how it has been interpreted and perceived by writers and critics outside of China. 


\section{The Question and Problematics of Chinese National Cinemas.}

Cinema's relationship to the Chinese nation-state and Chinese national identity has traditionally been addressed through various notions of Chinese national cinema. Ideas of national cinema have been heavily discussed and debated by many theorists and critics with Chinese national cinema being a site for contesting various frameworks. The discussion has attempted to identify what role cinema plays in the construction of a national identity. What is especially problematic in any discussion of Chinese national cinema is the reality that most films, if not all of them, are international from their inception. As Sheldon Lu has pointed out, "Chinese national cinema can only be understood in its properly transnational context" ("Historical” 3). This, he argued, is on account of several characteristics of Chinese cinema that make its dynamics unique. First, that 'China' does not refer only to one location, it consists of several different "geopolitical entities." Mainland China, Hong Kong, and Taiwan all compete for authoritative claim to "national/ local 'Chinese cinemas."' Secondly, film in today's global economy exists as always a transnational endeavor with financing and distribution found in many different global markets and combined in any one film production. Also, many in the Mainland, Hong Kong, Taiwan, and diaspora communities around the globe question and challenge the notion of Chinese identity and what 'China' and 'Chineseness' means. Lu's final point about the inherent transnational nature of Chinese national cinema was that the technology of film itself as a medium of expression originates outside of any Chinese locality and therefore is historically transnational (ibid.). Other attempts to investigate the borderless nature of contemporary Chinese cinema have done so through their nuanced individual approaches that find their differences in how they determine the parameters of what, more or less, ought to be considered as Chinese national cinema. Of the more contemporary theorists, most who have written and discussed Chinese national cinemas no longer operate with the assumption that national cinemas are straight forward and have appropriated Lu's framework foregrounding the international nature of national cinemas, or a framework very similar to Lu's. Gary $\mathrm{Xu}$, for instance, has adapted and modified Arjun Appadurai's conceptualization of 'mediascapes' to explore the visual culture of film in a culture-based market-driven environment. What Xu called 'Sinascapes' - "a complex web of transnational film production and consumption centered on and in China" (17) - involves the "filmic representation of China's social, political, and economic changes in the early twenty-first century" (ibid.). Shu-mei Shih investigated Chinese national cinema in terms of how it presents a complex juxtaposition of global and local in a correlation to language and visual: "with its visual form, it travels more readily across boundaries; 
with its linguistic particularities, it remains local in important ways" $(16)^{10}$. Each of these approaches have contributed to an understanding of the way that films help to construct a 'Chineseness' or a sense of communal identity.

Amidst the discussion of how cinema has contributed to a national identity, it is clear that there remains no easy consensus as to what a national identity is. Attempting to define national identity and national cinema is a project too big for the present thesis. What is important is understanding the way in which Zhang's authorship has been discursively tied into notions of Chinese national cinema and a Chinese national identity and how it has become impossible to separate his authorship from his relationship to the nation-state. As with the propensity to auto-read Zhang's films based on his authorship status, the nation of origin has played a significant part in the determination of how Zhang and his film's were received and interpreted. Rey Chow has stated that

"While [authors dealing with Western cultures] are thought to deal with intellectual or theoretical issues, [authors dealing with non-Western cultures], even when they are dealing with intellectual or theoretical issues, are compulsorily required to characterize... their intellectual and theoretical issues by way of a national, ethnic or cultural location" (as quoted and cited in Berry and Farquhar 14)

This general propensity to characterize non-Western authors in terms of their relationship to the national has certainly been a significant factor in how Chinese national cinema has been received. Zhang's discursive relationship to the nation-state has been so extensive that Zhang and his films have often been utilized by writers as examples and evidence of various notions of Chinese national cinema. The result is that Zhang has become either metonymic of the nation-state or the embodiment of Chinese national cinema or both, a representative purveyor of national identity even though there remains to be critical differences among writers as to exactly what 'national identity' might mean. Sheldon Lu, for instance, described Zhang as "the personification of Chinese national cinema" ("Zhang” 412), and Francis Gateward prefaced a compilation of interviews with his own observation that "rarely in the history of films has a single director come to be so thoroughly associated with an entire national output as Zhang Yimou" (vii).

Zhang's metonymy and embodiment of Chinese nation-state and national cinema should not be taken for granted. It is necessary to consider the metonymic dynamic directly. To address the problematics of national cinema in general, and Chinese national cinema specifically, Chris Berry

\footnotetext{
${ }^{10}$ Much like Shih, Sheldon Lu has recently modified his own parameters of Chinese national cinema incorporating Benedict Anderson's focus on the role of language in defining a national identity or what Anderson calls an 'imagined community.' (Lu, "Chinese Film” 2)
} 
and Mary Farquhar have interrogated the theoretical relevance of existing notions of national cinemas. With Sheldon Lu's influential framework of transnational cinemas in mind, Berry and Farquhar contested that even with all the academic dismissal of the national on account of its problematic characteristics, the national is still very important. They argued that even if the reality of nations and the cultural engagement with global economies subverts the national within the context of cinema, the national remains encoded into the transnational texts, remaining a vital component of its production and consumption. "The national informs almost every aspect of the Chinese cinematic image... therefore, Chinese films cannot be understood without reference to the national" (2). Their work provides a suitable new framework for investigating how Zhang has become so associated with Chinese national cinema and national identity and how the fascist framework's emphasis on his relationship to the nation-state might be understood. On account of all the inherent problematics, they proposed the

"abandonment of the national cinemas approach and its replacement with a larger analytical framework of cinema and the national. Instead of taking the national for granted as something known and unproblematic - as the older national cinemas model tended to - our larger analytical framework puts the problem of what the national is how it is constructed, maintained, and challenged - at the center. (3)"

This is valuable because its application stresses the relationship between the visual medium of film and the shifting, heterogenous project of the national. This relationship has significant ramifications on how a film is read. As Berry and Farquhar argued, it is more important to consider the relationship that cinema has with the national than it is to attempt defining a national cinema. They also argued the importance of addressing the relationship of Western scholars to the film texts in the discourse of national cinema. The fascist argument emerged out of a tendency to take for granted that Hero is a film that represents the national, taking for granted its relationship to the nation-state. Re-inscribing Zhang's films within the framework of 'cinema and the national' requires a critical re-evaluation of the discursive propensity to 'auto-position' them against the nation-state, either subversive or submissive. Looking at how the fascist controversy was the result of Zhang's constructed relationship to the nation-state is also an investigation of how Hero's representation of the national has been assumed. As the fascist argument conflates Zhang with his films, the framework of 'cinema and the nation' is suitably adaptable for my purposes to include the idea of 'auteur and the nation.'

Taking the new perspective of evaluating Zhang's authorship in terms of its relationship to the nation-state - not taking that relationship for granted - it becomes clear that the recurring motifs 
of Zhang' authorship each have played a vital role in contributing to the discursive construction of this relationship. This relationship, highlighted by the reconfigured motifs, represented a shift across the peasant/government binary. Importantly the metonymy that Zhang embodied, prior to Hero and prior to the fascist framework, was a metonymy with the Chinese peasant predicated upon his alignment with the people and the Chinese soil. After Hero, with the fascist framework, Zhang's metonymy was with the Chinese government predicated on his alignment with the state, and with the project of nation-building. Metonymic of the Chinese peasant meant that he was subversive. Conversely, metonymic of the Chinese government meant that he was submissive.

Analyzing Zhang's relationship to the state before and after Hero involves a complicated matrix of investigation. Chan argued that some of Zhang's pre-Hero films such as The Story of Qiu Ju (1992), Not One Less (1999), and The Road Home (1999) had propagandistic resonances. This problematizes any attempt to classify Zhang's films as anti-government before Hero and progovernment after Hero. Yet, Chan seems to have indicated that Hero was the moment where Zhang's fascist trajectory found its apotheosis, the tipping point to where Zhang 'gave in' to the 'temptations' of the state, or rather succumbed to the "throttling hold of gerontocracy" (18). Correlating the fascist framework with the release of Hero suggests dividing the perception of Zhang's relationship in a way that unnecessarily oversimplifies the dynamics of Zhang's authorship discourse. Yet Chan's suggestion that Hero was a turning point in Zhang's career indicates that Hero can serve as a useful text to evaluate as the culmination of Zhang's alleged fascist predisposition. Outside the fascist framework and outside the discourse of Zhang's constructed authorship, the decision to praise or condemn Zhang's films has not always relied on his perceived relationship to the Chinese nation-state. However, within the fascist argument the decision to praise or condemn the film has been linked to the perception of Zhang's shifted relationship to the Chinese nation-state where characteristics of Zhang's constructed authorship re-emerged transposed in a way which justified the fascist allegations.

\section{Pre-Hero: Zhang's Discursive Journey from Subversive to Submissive.}

As the last chapter demonstrated, Zhang's authorship biography often provided necessary justification for reading Zhang as a subversive filmmaker. Understanding this subversion as a relationship to the Chinese nation-state provides the basis for understanding the discursive construction of Zhang's perceived relationship. As subversive, his relationship to the Chinese nation-state was constructed as antagonistic to the government, but representing an authentic peasant-centric national identity. The metonymic connection of Zhang to the Chinese peasant needs 
to be interrogated in order to understand the discursive shift that the fascist framework alleges with Hero.

In 1993, Zhang had just released The Story of Qiu Ju, his first film after the auteur-defining 'Red Trilogy.' Writing for Times magazine, Richard Corliss reviewed the film and described Zhang as "China's ambassador to sophisticated moviegoers." Even more contemporarily, Zhang is still referred to in similar terms. When Spielberg wrote about Zhang's involvement in the 2008 Olympics, post-Hero, his pronouncement that Zhang "told China's story" resonated with the ambassador quality prescribed by Corliss's pre-Hero sentiment. To call Zhang an 'ambassador' is an interesting, if not highly problematic, distinction. Ambassador implies that Zhang somehow represents China and Chinese culture to the world. But what 'China' is Zhang an ambassador of? The answer to this question reveals the way in which the fascist framework has foregrounded the authorship of Zhang Yimou as it perceived a shift in Zhang's relationship with the nation-state. PreHero, the 'China' that he represented was the people oppressed by an authoritarian government. Post-Hero, Zhang's 'ambassadorship' centered around the perception that Zhang was promoting that oppressive government to the rest of the world, on behalf of China. Regardless of the supposed shift, both before and after Hero, Zhang was discursively positioned as a purveyor of Chinese culture to the world, while the actual definition of China changed depending on which alignment Zhang was seen as embodying.

Prior to Hero the qualities that justified Zhang as Chinese ambassador recall Wang Bin's description from the previous chapter. Wang identified Zhang as an authentic Chinese peasant precisely because his stories of the common Chinese individual in rural settings were representative of Zhang's own connection to the Chinese countryside. Reinforcing the idea that Zhang, through the distribution of his films internationally, represented Chinese culture Wang proclaimed that "if you don't know the Chinese peasant, you don't know China" (Behind the Scenes). The implication is that for a Western viewer to understand China, they need not look any further than Zhang Yimou and his portrayal of peasants in the countryside.

Zhang's films were perceived as offering access to stories of a 'real' peasant-centric Chinese reality, which meant having unparalleled access to China. Sheldon Lu explained that through his films, Zhang "has offered the Western viewer a 'museum' of precious Chinese objects, costumes, and artifacts" (Lu, "National Cinema" 126). This 'museum' has included the sedan chair song sequence from Red Sorghum, the mourning ritual at the funeral procession from Ju Dou, and the lantern raising and foot massages from Raise the Red Lantern. Zhang's authorship might then be re-conceptualized in terms of its national significance as The Zhang Yimou Museum of China and 
Chinese Culture, which shows the West all about "his "China"” (ibid.). His China, according to his early films, was centered on the plight of the Chinese peasant. As a 'museum,' or as an ambassador, there has been a certain authenticity ascribed to Zhang and his films. Authenticity has been highly problematic in the films and associated 'ambassadorship' of Zhang. Authenticity here is defined by how closely aligned to a perceived Chineseness that Zhang was interpreted as being. The great irony is that many of those items in the museum of Zhang - the sedan chair song, mourning ritual, raising the red lanterns, and the foot massages - were artificially constructed, having no historical precedent as its basis (see Chow 144, 231). The tautology inherent in Zhang's authenticity is that his authenticity which was defined by his position as a peasant is discursively justified by the artificial representation in the films that he created. His relationship to China, then, is defined by the way in which he has portrayed a museum of artifacts, real or not.

Zhang's authenticity and alignment with the Chinese peasant has been reinforced by the criticism that, through his films, he has revealed what should not have be disclosed to Western audiences. In his own words, Zhang described that criticism of his early films was often characterized by the accusation that he filmed "only the dark or backward aspects of China" (qtd. in Li 83). These accusations appear to have come mostly from Chinese critics. But this internal criticism has authenticated Zhang's portrayal of China because it characterized what he portrayed as the gritty reality of China, not the glamorous portrayal that might be found in propagandistic presentations. Rey Chow has analyzed common threads in criticism that was targeted at Zhang and his first few films. She discovered three interrelated characteristics. First, that his films "lacked depth." This shallowness was often perceived as symptomatic of the visual beauty of his films. The Red Trilogy was read as being too focused on aesthetic representation, and as such was superficial, with no potential for profound messages. Second, the superficiality of his films are "self-Orientalising." Zhang has often been criticized as making his films primarily for the gaze of the Western other. His films allegedly presented the Chinese peasant as othered and exoticized to appeal to a Western audience's appetite for stories from the margins. The aesthetics, already spectacular and exotic, even erotic, as well as the narratives of illiterate and backwards peasants was mere cultural 'exhibitionism.' Third, his films were criticized for exploiting marginalized and oppressed women (Primitive 150-1). Rey Chow argued that all three of these aspects were related to the Chinese saying jia chou bu ke wai yang, which finds a close English equivalent in the saying “don't air your dirty laundry in public" (ibid. 152-3). This opposition of Chinese critics, as well as some Western ones, to showing the ugly side of Chinese culture and society presented Zhang as a director who has revealed, to the Western other, the raw, ugly, and 'real' China that other 
filmmakers have hidden. When Hero was released, this characteristic of Zhang's auteur relationship to China was important as Hero's more spectacular portrayal of China - resembling tourist advertisements (see Xu 37-40) - contrasted his portrayal of the 'ugly' side and contributed to Hero's reading as inauthentic fascist propaganda.

The idea that Zhang revealed a 'real' China to the West has been supported by his infamous struggle against government censorship. His relationship to Communist Party censors, prior to Hero, has helped to define Zhang's auteur status as politically subversive, aligned with the Chinese people at odds against the Chinese government. His Red Trilogy, and how the trilogy's films were treated by the Chinese government, is evidence of this. Critically, the three films were praised and honored with numerous awards, even at the Academy Awards in America. Yet the film censorship branch of the Chinese government deemed Ju Dou, and Raise the Red Lantern too inappropriate for local distribution. Regardless of the actual reasons for the government's aversion to the films, the effect of the prohibition valorized Zhang's auteur voice as a subversive one in the international market. In reality, both of these films were permitted to be screened in China in 1992 when the government chose to lift the ban. However, because they were once banned, the temporary governmental intolerance became an immortal attribute that accompanied and characterized Zhang's authorship. Nothing seems to support that your films are antigovernment more than having those films outlawed by the government. Later in his career, Zhang responded in frustration to the West's misunderstanding of Chinese films: "for (Western audiences), Chinese films must fall under two categories: they are either government propaganda or antigovernment. By this logic, whatever films the Chinese government approves must be bad, and whatever films are banned in China must be good and worth seeing" (qtd. in Lu, "Chinese Film" 126). This accusation reveals the propensity, arising out of the manner in which Zhang's authorship has been constructed, that Zhang was either antigovernment or forced to defend such a construction. Either way, the banning of his films has played an important role in identifying Zhang as politically subversive. Furthermore, like 'airing dirty laundry,' it also has justified reading Zhang's films as possessing cultural fidelity, as though they embody a 'truth' that even the Chinese government wanted to suppress and keep hidden from the West.

The government censor's adverse reaction to one of Zhang's later films, To Live, was a significant reason that it was acknowledged by many writers as one of Zhang's most important works. In his argument for Hero's political submission, Evans Chan cited To Live as an example of how Zhang was once artistically relevant and politically subversive. Chan called the film "the most daring and masterly film among the Zhang corpus" (15). His evaluation of To Live was in a section 
of his essay which was circumscribed by Chan's estimation of Zhang's relationship with the government censors. His argument began by extolling many of Zhang's early films in a career summarized as a "complex dance with the official censors" (14). Chan's contextualization of his argument that Hero was fascist in terms of Zhang's experience with censorship foregrounds how important the role of a film's relationship to censorship has been in determining the relevance of the film. Zhang Xudong wrote of the propensity to auto-read Chinese films in terms of their relationship with the nation, but also identified how that relationship also has determined critical attitudes of like and dislike for the films.

It remains an unchallenged habit - both inside and outside China - to view everything in the P R C through the imagined totality of the government and its official policies and rhetoric. It is also customary, even a knee-jerk reaction, to see anything extragovernmental as instantaneously and naturally subversive, progressive, and good. (Postsocialism 27)

Zhang Yingjin also wrote of this propensity for Western scholarship to identify likes and dislikes in terms of the way the film was treated by the Chinese censors. Zhang Yingjin explains that not only has the banned status added to the West's inclination to acclaim the film, but also to deem it 'truthful' or authentic in its depictions of Chineseness. 'Ironically, the rumored or 'banned' status often adds to the political capital of these films, which often win sympathy, prizes and future financial backing in the west and are acclaimed as 'truthful' depictions of contemporary Chinese life" (Chinese 3). In terms of Zhang Yimou's constructed authorship, the tendency to read his films as politically subversive has been rooted in Zhang's reputation as a censored auteur. What is most interesting is how the perceived political imperatives of his early films seem to have followed Zhang throughout the rest of his career. Each of his subsequent films would be read in comparison to how their subversive meanings 'stack-up' against his Red Trilogy. In fact, according to the fascist framework, To Live was the quintessential moment of Zhang's struggle against the Chinese censors. Therefore, Zhang has been posited as not only culturally authentic but also politically subversive. In showing what China does not want us to see, he became more authentic through his political subversion, which has aligned him with the Chinese peasants.

After Chan established that his argument was based on Zhang's relationship with state censors, he focused his critical energy on the myths that where constructed in the films of Zhang Yimou. Evans Chan's evaluation of Zhang's pre-Hero career alleged that "from the very beginning, Zhang Yimou is a self-elected national-myth maker" (18). Myths have an important function in 
national cinema and the discourse of national identity. Sheldon Lu might have agreed with Chan's myth-maker idea. Citing Susan Hayward's work on French national cinema, Lu noted that

like other national cinemas, Chinese cinema is the 'mobilizer of the nation's myths and the myth of the nation.' Through the creation of a coherent set of images and meanings, the narration of a collective history, and the enactment of the dramas and lives of ordinary people, cinema gives a symbolic unity to what would otherwise appear to be a quite heterogeneous entity: 'modern China.' ("Historical” 5)

While analyzing Zhang's use of myths in films, Chan takes for granted that Zhang's films have incorporated national myths, which conceals a more interesting reality. Zhang has been a national myth maker, but not necessarily because he intended to be. He has been a national myth-maker because of how his films have been positioned discursively within the project of nation building. So, whether he had intended to be national myth-maker or not is relatively insignificant. He has become this myth-maker through the discursive positioning of his auteur status and the transnational interpretation of his films. There are two oft-cited ways in which Zhang's films have manifested these myths: through portraying myths of origin, and the presentation of unique rituals. Origin myths and unique rituals provide artifacts of a culture that justify it as unique, with a unique claim to a history that no other nation or culture is able to claim. Gary $\mathrm{Xu}$ has argued that this way of encoding the local, or national, within the global, or transnational, has been a process of securing copyright in the global marketplace where 'authentic' culture is a precious commodity (29). The commodification of culture highlights, again, the reality that the value of Zhang's cinematic rituals and representation of history has been rooted in artifice. While the awareness of such artifice might threaten to undermine the authenticity so important to Zhang's authorship, instead it strengthens it. "Some films achieve transnational status precisely because they are seen as possessing an authentically 'national,' 'Chinese,' ‘Oriental' flavor by Western audiences” (Lu, "Historical” 12). The additional implication here is that a film's membership in the transnational relies on its ability to convey a fabricated representation of the 'national' which suits the tastes and expectations of Western audiences.

Through the use of myth and Zhang's discursive alignment with Chinese peasants, Zhang has presented stories of China that were rendered authentic through his auteur construction. Prior to Hero and the fascist framework, Zhang's China was peasants, strong-willed and often backwards. His China was futile resistance against outmoded oppressive traditions. His China was exotic. His China was sexual. His China was spectacularly visual. As metonymy of Chinese peasants, Zhang and his films have represented China and Chinese identity to Western audiences from the position 
of subjects of the state. He was the voice of the people. An ambassador for those who were antagonized by the government of the Chinese state. That is until, as Chan put it, "the tightening grip of the state finally caught up to him" and he succumbed to the temptations of fascism (18).

\section{Hero and the Gerontocratic Submission Grip.}

With such a strong subversive relationship to the state determined by the discourse of Zhang's authorship it is little surprise to see that Hero was read as a shift. In many ways the first indication that Hero was incompatible with Zhang's previously constructed authorship was Zhang's employment of genre. Zhang's reputation as a non-genre director meant that making an epic genre film was simply explained as the result of a shift. The authorial shift represented by Hero and characterized by Zhang's use of a popular cinematic genre was marked by a perceived shift in the relationship between the auteur and the Chinese nation-state. As such, what Zhang did with genre was less important than that he used genre. His career as a non-genre auteur was then supplanted by his deliberate attempt to take advantage of a genre newly initiated into international popularity. His move to the wuxia genre was a 'sell-out' step because wuxia had proven to be a 'money machine.' No longer artistically pertinent, politically profound, or culturally interrogative, Zhang, the 'fallen auteur' was altogether perceived as having prostituted exotic Chinese 'otherness' with a focus on blockbuster bottom lines.

Gary Xu analyzed Hero in terms of how it portends a cultural authenticity in order to secure successful proliferation in the global marketplace via unique, copyrightable, cultural expression that promotes China as a commodified national identity. With the production of Hero, Zhang has specifically said ${ }^{11}$

"I was clearly aware that I made Hero for foreign viewers. As soon as those Americans hear that Jet Li, Tony Leung, Maggie Cheung, Zhang Ziyi, and Donnie Yen will appear together in a martial arts film, they want to see the film. . . . But I decided not to cater exclusively to their tastes. If I were to satisfy their tastes, I would have focused more on direct physical contact in the fight scenes. Instead, I decided to focus more on spiritual communication and less on physical contact. In fact, I wanted to lure those Americans into the theater before imbuing them with some ideas of genuine Chinese arts. Impress them a little. Give them some information. This is only the first step. There are things in Chinese culture that cannot be easily understood. It would be a

\footnotetext{
${ }^{11}$ It is worth including this quote in full because it highlights the fact that Zhang's decision to make Hero was far more complex than the simple notion that he 'sold out'. It demonstrated an awareness and consideration of the difficulties and complexities of cultural expression in a diverse international arena.
} 
great achievement if a foreigner can figure out the meaning of yijing (which $\mathrm{Xu}$ translates as 'ideascape') after living in China for ten years. I don't expect them to understand. All I want is gradual influence, bit by bit. They would certainly be surprised by the way our martial arts are presented. Why isn't there any bodily contact? It's strange to them. Why do calligraphy and sword moves share the same principles? Where is the connection? These are things that we Chinese all take for granted. What I have done is sell Chinese culture with the help of the martial arts genre film." (in Xu

$\mathrm{Xu}$ argued that Zhang's emphasis on cultural authenticity was part of an attempt to create a unique filmic text that would validate and reify a sense of Chinese national identity that would enable China to compete in the age of global capital. "Marketability is based on genuineness, and genuineness increases marketability" (37). Zhang's admission that he was aware of the West when making Hero was an acknowledgement of the West-facing direction of the film's discourse. He also admitted to the desire to 'teach' Chineseness to the West, as a sort of declaration of acknowledged ambassadorship. The Zhang Yimou Museum of China and Chinese Culture was still open, but his alignment was no longer with the Chinese peasant. Previously, he was seen as promoting a Chinese national identity in spite of the Chinese government's concerns, and often at odds with them. Now, with Hero, Zhang was positioned as promoting a national identity in harmony, and in cooperation, with the government; ambitiously trying to position China in political, cultural, and economic relevance in this, 'China's Century' (Xu 1-5).

That Zhang was perceived as cooperating with the government in this project of nation building was evidenced most clearly through its distribution. Hero represented a submission to the Chinese government precisely because Hero's distribution was sponsored by the state and promoted by the government. The Chinese government's support of the film was made clear when they sanctioned an official screening in Beijing in the Great Hall of the People at Tiananmen Square. As a prominent location used by China's Communist Party for legislative and ceremonial purposes coupled with the site's political potency - especially in Western minds quick to recall the iconic and hotly contested Tiananmen Square pro-democracy student protests of 1989 - the screening in the Great Hall positioned the film as communist propaganda. Comparing the treatment of Hero to some of his other films, especially To Live, it is easy to see how such a display of support from the Chinese government could have been such damning evidence proving the filmmaker's turn to submission. 
The government-endorsed distribution of the film meant that the film's promotion in the international marketplace was contextualized as aligned with the Chinese government. Further supporting the justification of this alignment was an interpretation of the aesthetics of the film. Part of the aesthetics, the genre, has already been discussed, but the style of the film's presentation of narrative is so drastically different from his other films - being more spectacular and sensational than the Red Trilogy, for instance - that it has been of particular interest in the reception of Hero. Evans Chan mentioned the idea of 'fascist aesthetics' in his analysis of Hero. While he never directly referenced Susan Sontag, much of his analysis of Hero's politics resonates with Sontag's work and appears to have been at least marginally informed by it. ${ }^{12}$

While Chan did not directly connect Hero with Sontag's work, many others who have been proponents of the fascist framework have made direct reference to her work. At any case her writings on fascist aesthetics is instructive in understanding how Hero's visual presentation has been perceived as evidencing a submission to authoritarian government. In Susan Sontag's analysis of Leni Riefenstahl's work she identified fascist aesthetics as a visual style which is informed by, and justifies, "a preoccupation with situations of control, submissive behavior, and extravagant effort; they exalt two seemingly opposite states, egomania and servitude." Fascist art emphasizes individual submission and "has the function of 'immortalizing' its leaders and doctrines." This fits with Chan's argument that Hero was fascist because it portrays "a leader with a charisma that is exceptional enough to summon total surrender of body and mind" (20). The "egomania and servitude' dichotomy at play in Hero is reinforced for a fascist reading by what Sontag calls "characteristic pageantry:"

The massing of groups of people; the turning of people into things; the multiplication of things and grouping of people/things around an all-powerful, hypnotic leader figure or force. The fascist dramaturgy centers on the orgiastic transactions between mighty forces and their puppets...The rendering of movement in grandiose and rigid patterns is another element in common, for such choreography rehearses the very unity of the polity.

Hero contains many presentations of this sort of pageantry including the marching of the emperor's army, the ceremonial launching of arrows in a unifying grandiose spectacle of destruction, and the choral chants of the faceless mass of shield and sword wielding archers. As if to foresee Chan's argument against Hero's perceived politics, Sontag says that "fascist art glorifies surrender; it exalts

\footnotetext{
${ }^{12}$ Chan's mention of 'fascist aesthetics' and the regular comparison to Leni Riefenstahl, for instance, indicate at least an implicit connection to Sontag's work.
} 
mindlessness: it glamorizes death." In Sontag, Chan might have found justification for his reading of the sacrificial suicide of Hero's main character, Nameless, as well as the deaths of Broken Sword, and Flying Snow. The interpretation that the film's genre, distribution, and aesthetics are fascist foregrounds the reconfiguration of the three motifs toward the new positioning of Zhang as pro-government. This repositioning emerges out of the discursive reliance on, and assumption of, Zhang's relationship with the Chinese nation-state.

\section{Towards a New 'Hero.'}

The previous chapter explored the discursive construction of Zhang as a particular auteur. Evaluating his authorship and the recurring motifs that has defined that authorship reveals the foundation of the discursive perception that was the context for the fascist framework. This chapter investigated the fascist framework's response to Hero, and the unchallenged reliance on Zhang's authorship and his discursive relationship to the Chinese nation-state. That response criticized Hero as an example of Zhang submitting to China's communist government. In Evans Chan's critique he argued that there was a gradual process whereby Zhang became more and more fascist. Paul Clark, writing under the same perception that Hero's politics support an authoritarian ruler and government, cited Hero as an indication that "there could be no better evidence of the end of the fifth generation as a significant group of Chinese artists" (186). There is sufficient evidence to suggest that this fascist argument is symptomatic of the way in which Zhang was constructed as an auteur of national cinema.

The problematics of national cinema frameworks and the auto-reading propensity associated with discourses of authorship and national cinema indicate the need to reevaluate the film to see if the film contains any other meaning other than that which has been dictated and determined by Zhang's authorship construction or notions of Chinese national cinema. While the last chapter explored the reception of Hero, the next chapter will look more directly at the film text and deconstruct some of the problematic assumptions of the fascist framework. An understanding of, among other things, the film's ambiguities reveals that the fascist framework's reliance on Zhang's pre-constructed authorship and discursive relationship to the nation-state unnecessarily forecloses other complex potential meaning. 


\section{Chapter 3:}

\section{Alternative Interpretations of Hero.}

So far this thesis has explored the auto-reading and auto-positioning impulse of Western writers. The propensity to rely on the discourse of authorship and national cinema has contributed to the discursive creation of the fascist framework when responding to Hero (2002). However, there have been other writers who have resisted the fascist framework and their analyses of Hero have offered alternative perspectives on Zhang's first wuxia film. Taking into account the problematics of auteur discourse - including, very importantly, the omission of texts that do not 'fit' Zhang's authorship - as well as the complex problematics of national cinema discourse, these other analyses offer an impetus for re-evaluating the film in terms of what it may offer, what it may be saying. By utilizing the work of these writers and using my own analysis of the film, shortcomings of the fascist argument become apparent. These shortcomings manifest as characteristics that the fascist argument has assumed, foreclosed, or has simply taken for granted. When interrogated, these characteristics, whether implicit or explicit, challenge the fascist argument's reliance on Zhang's previously constructed auteur status and his discursive relationship with the Chinese nation-state.

In this chapter I will explore these shortcomings as what I will refer to as the four major assumptions. First, the fascist argument assumes that a Chinese filmmaker, such as Zhang Yimou, has been relatively uninhibited in the process of filmmaking. This forecloses the pressures that a Chinese filmmaker encounters which might effect and limit what a filmmaker can do or say. Here I will briefly look at the circumstances of the production of the film. After considering market pressures on the author, I will look at the way in which Hero portrays China's first emperor, Qin Shihuang. The fascist argument, Chan's essay particularly, has placed a lot of emphasis on how the representation of this historically important figure evidences a fascist persuasion. The second major assumption of the fascist framework is that the film's portrayal of China's first emperor is straightforward. This is not the case. Instead, Hero's portrayal of the first emperor is better understood in the context of a dialogue which the film engages in about the qualities and limits of a ruler. After investigating the portrayal of the emperor, the next section of this chapter will focus on the other primary character, Wuming or Nameless. The third major assumption is that Nameless's heroism in the film is on account of his surrender to the emperor in order that the emperor might successfully 
continue his blood-thirsty quest for national unity. There are two components of this assumption of the fascist argument that I will address: first, that it takes for granted that Nameless is the titular hero, and second that it assumes that it is Nameless's intention from the beginning to surrender to the emperor. The fourth major assumption is a misunderstanding of the film's central theme or idea, involving the Chinese concept of tian xia. It assumes that tian xia - translated as 'Our Land' in the English subtitles - means the same thing for both emperor and assassins. This conflates tian xia in an essentializing misrepresentation of a complex idea. Importantly, the assassin does not die as a sacrifice for the emperor's tian xia but gives his life to a futile hope that the people's tian xia might be accomplished. An investigation of these four major assumptions enhances an understanding of the problematic reliance of the fascist framework on discourses of authorship and national cinema.

\section{Zhang's Pressures.}

Making and producing films in the People's Republic of China has not been the same as making or producing films in Hollywood or any other film industry in the West. Throughout his filmmaking career, Zhang has had to negotiate and balance his own personal interests with pressures and demands of the market, international and domestic, as well as satisfying government censors who held the power to control distribution of a film and who often determined the future of a filmmaker's career. While Evans Chan extolled the subversive potency of Zhang Yimou's To Live (1994), he ignored the effects of such a film on Zhang's career. Zhang's experience with the release and distribution of To Live is an example of what happened when a filmmaker in the PRC did not placate the government censors.

Several of Zhang's films have been banned by the Chinese government from viewing inside China. To Live, however, is Zhang's only film that remains to be officially prohibited. ${ }^{13}$ For To Live, Zhang had submitted a film script for approval by the government censors which uncritically portrayed China's bright future. The script that was submitted and approved was not the script that ultimately became To Live (Barboza). Zhang's betrayal of the censors, the film's critical portrayal of the Cultural Revolution - a taboo topic for China's film censors - as well as his attempt to promote the film to international festivals resulted in the government forcing Zhang to make a formal public apology (Cardullo 116). Also, as punishment, for the next five years Zhang was prohibited from using any foreign funding for his films (Barboza, Brook 24). When making Hero, the memory of that experience could not have been far from his mind.

\footnotetext{
${ }^{13}$ Although many Chinese people, in China, are familiar with To Live having seen the film through unofficial screenings and/or unofficial recorded video mediums (Tempest 64).
} 
In an interview, Zhang spoke of his experience with the censors. While the government's reaction with To Live frustrated Zhang's career, he was optimistic that censorship in the future will not be an issue. But with regards to making films until censorship relaxes, he said: "the question now isn't whether you're good at balancing things: you have to balance what you say against what you cannot say. This is a reality directors have to face" (qtd. in Cardullo 139). This balancing act that PRC filmmakers have been required to make has had significant bearing on the content and form of their films.

As well as the political pressures, there have been strong market pressures that film directors in the PRC needed to negotiate. Throughout the 80's and 90's the Chinese film industry shifted. Outside investment was increasingly allowed and studios moved away from state ownership and became open to private investment. When Zhang began directing films in the late 80 's he did so by assuring studio heads that he was able to provide them a vehicle to succeed in the marketplace. "When Red Sorghum was filmed," Zhang recalled, "I ... gave Wu Tianming (the head of Xi' an Film Studio) three guarantees - no trouble from the government, artistic quality, and commercial boxoffice success" (qtd. in Jiao 10). Zhang's 'guarantees' indicate that there was a need for a strategy for competing in the market, something that was not previously necessary with full statesponsorship. While the state still operated strict censorship restrictions, the success of a film's production, distribution, and exhibition was increasingly subject to market pressures (see Jiao 10; Lee; Lau, "Hero"). Zhang's 'guarantees' also indicate an awareness and a need for placating government censors. Importantly, seeking to pacify censors with his first film contradicts the fascist framework's reliance on the notion that Zhang was then a subversive filmmaker. At least with Red Sorghum, it does not appear that subversion was Zhang's intention. During the 90's, the market pressures on filmmakers led to a fragmented industry uncertain of how to produce a film that would excel. Jenny Kwok Wah Lau's summary of Chinese films during the 90's demonstrates the grim reality of the films that were produced in the period leading up to Hero's release. She wrote "from the early 90s one can identify three major types of cinema in China: the artisan/cultural films, usually banned; the state-sponsored films (old mainstream), usually not popular; and the new mainstream entertainment, commercial and stylistically imitating Hollywood" ("Hero"). The increase in imported Hollywood films was met by a rise in Hollywood's dominance over Chinese films. Chinese films, unable to compete directly, were not making it beyond the art-house, festival distribution circuits in international markets (Lau, "Hero"). Furthermore, because Chinese films were not competing internationally, they were not recovering as much revenue as their Hollywood counterparts. The rise of consumerism in China meant that arthouse films were no longer 
economically viable (Lu, "Historical" 9-11). In order to compete locally, Chinese films also had to compete internationally so that they could recover the costs of production. ${ }^{14}$

The success of Ang Lee's Crouching Tiger, Hidden Dragon (2000) in Western film markets revealed an opportunity for Chinese films with a glimpse of how, using wuxia's martial arts aesthetic, Chinese film could compete with Hollywood blockbusters. Following Crouching Tiger's lead, Hero was positioned as China's entry "intended as the opening salvo (and as good business) for the new Chinese blockbuster film aimed at the Hollywood Goliath" (Khoo), a film to "save the market" for Chinese films (Wu Tianming in Behind the Scenes).

In order to 'save the market,' it was necessary that Zhang's production strategy for Hero balanced market competitiveness with the restrictions imposed on him by government censors. Vivian Lee points out that the ambiguity, or 'indeterminacy,' of the film is what has facilitated the success of the film's presentation in the global marketplace as part of a successful strategy. The film's ambiguity has contributed to its success because it has enabled Hero's narrative and presentation to be received and interpreted internationally, despite the differences that might exist between various cultures. The fascist argument reads Hero as a final surrendering of an artist to the government, but an alternative reading is that he has simply utilized a successful strategy of ambiguity to convey his message internationally while negotiating market and political pressures in order to have his film financed, approved, and distributed.

\section{Hero's Representation of Qin Shihuang.}

While the international success of Crouching Tiger, Hidden Dragon made the wuxia film a viable production strategy, Zhang Yimou has also revealed a personal motivation behind Hero. In an interview he confessed a fascination with wuxia tales, an interest that he has held since he was a boy (Cardullo 134). Until Crouching's pioneering success, making a film in the wuxia genre was not considered financially viable. But once Crouching had opened the market to wuxia films, Zhang was able to explore the possibility of realizing into film his boyhood interest in the genre.

Stephen Teo has pointed out that there is an inherent boyishness which is an important marker in the orientalizing aesthetics of wuxia films and their portrayal of China and Chinese history (Chinese Martial 178). Ang Lee has even acknowledged that the China in his film portrays a "dream of China;" far from a historicist portrayal, the film shows a representation of history and the nation that only exists in "boyhood fantasies" (qtd. in Teo, Chinese Martial 178). It is important to

\footnotetext{
${ }^{14}$ Not to mention the pressure on Chinese filmmakers of the need to counter piracy. See Xu 25-6 for the producer's strategy against piracy with Hero.
} 
consider Zhang's personal impetus behind his production of Hero as it helps us understand the problematic portrayal of one of the film's most central characters, Emperor Qin Shihuang, loosely based on China's first emperor.

As so much of the fascist argument has relied on the film's portrayal of Qin, and the film's portrayal of Qin is part of an interpretation of history meant as fantastical, interpreting the way that Qin is portrayed in the film creates some complex problems. The assumption made by the fascist framework is that the representation of Qin Shihuang is meant as a straightforward historical account - straightforward as though the film is meant as recounting an accurate portrayal of this historical personality. Qin in the film is portrayed as a caring individual with a humane interest in his subjects, where historians have presented the historical Qin as little more than a ruthless dictator driven by desires of power. In a straightforward interpretation, the disparity between the historical Qin and the film's Qin prompted Evans Chan to argue that Hero reappraises the place of Qin Shihuang in Chinese culture... as a misunderstood philosopher-king, whose weepy self trembles under the false guise of being a tyrant when his real intention is to bring universal peace... through war and conquests, i.e. building an empire. (19-20)

Chan extended his criticism of the film and implicated it as an allegory which he claimed is meant to endorse contemporary Chinese government, "endowing it with a new messianic mission" (21). However, as a wuxia film, Hero is a spectacle - highly saturated colors, showcases of exceptional fight choreography, and exaggerated editing with slow-motion movement being a few elements that emphasize the spectacle of the narrative - not a documentary. The historical Qin is not on display, but an imagined Qin whose motives are irrelevantly dissimilar to the historical person (Lau, "Hero"). Furthermore, Hero, much like Crouching, and other wuxia are the realization of a portrayal of China, Chinese culture, and Chinese history more akin to fantasy than historicist reality (see Teo, Chinese 178). Zhang has even admitted that his motivation to portray Qin had little to do with the historical character, rather it was the imperial colors that attracted Zhang to Qin's time period. Known as a visual director with a reputation for his use of color, Zhang was attracted to the setting of Qin's court because the color of their uniforms was black. The decision to feature China's first emperor as a dominant character in the film was coincidental, marginal, and less significant to his desire to portray his wuxia where one of the dominate color schemes was based on the black uniforms of Qin (Zhang Yimou qtd. in M. Berry 116).

While the selection of the film's setting might have been arbitrary, it would be impractical to discount Zhang's awareness of the historical implications of portraying such a dominant political 
figure. The fascist argument considers Zhang's awareness as limited to merely attempting to promote the emperor and his policies and, by allegorical connection, promote China's modern political leaders. There are, however, other ways to interpret Zhang's portrayal of Emperor Qin. In Vivian Lee's analysis of the film, she argued that the film demonstrates both hyperbole and irony in the way it eulogizes the emperor. Just before the final credits appear at the end of the film, there is text superimposed over images of the Great Wall stating that the emperor "protected the country and the people." Lee considered this to be deliberately and obviously false, a statement made by the filmmakers fully aware that the audience's familiarity with history would enable them to see that the entire film is not meant to be taken as a literal exposition on history.

With Hero, Zhang appears to have intentionally entered a dialogue with his audience and with other film artists. Zhang must have known that his audience, at least in China, would have been familiar with the founding myth of China and the legend of the emperor credited with building the great wall, unifying the written language, the terra cotta warriors, etc. Not only would familiarity be gained from school rooms or textbooks or other sources but there were several other prominent film artists exploring the story of Qin Shihuang. Importantly, Hero was only one of several high profile Chinese films that had focused on a similar story of a failed assassination attempt on China's first emperor. In 1996, Zhou Xiaowen directed The Emperor's Shadow, a very expensive film which featured many well-known Chinese actors such as Jiang Wen, and Ge You who worked with Zhang in Red Sorghum (1987) and To Live respectively. Initially Zhou's film was banned by the Chinese censors but the ban was later lifted and the film was allowed to be distributed (Palmer). In 1998, Chen Kaige directed The Emperor and the Assassin, another highbudget film with a famous cast, including Zhang's longtime collaborator, Gong Li. It is evident that Zhang was familiar with these other films, he was either directly and indirectly connected to each of them. Fellow Fifth Generation filmmaker, Chen Kaige had even approached Zhang to play the part of the emperor in his film. Zhang was not ultimately in the film, but offered suggestions to Chen on style and design direction (M. Berry 116). Zhou Xiaowen's film inspired Tan Dun to adapt the story into an opera for the Metropolitan Opera. Tan Dun's opera, titled The First Emperor, was directed by Zhang Yimou and premiered in December of 2006, just two years after Hero screened to western audiences. These two portrayals of the first emperor and assassins are both based on the same history written by Sima Qian. Chen's and Zhou's films, and subsequently Tan Dun's opera, portray less than glamourous assassins and their futile attempt to assassinate a dictator consumed by power. Zhang's Hero features similar narrative circumstances - that of an assassin's failed attempt at killing the emperor - but it is the only one that was produced in the wuxia genre and Hero's plot 
does not rely on the same source material as the films by Zhou and Chen. Zhang's film also differs in that it portrays the emperor sympathetically, not negatively, and Zhang's assassin demonstrates an exceptional mastery of the martial arts - something that the assassins from the other films lack (see Teo, Chinese 186).

It appears that Zhang, little interested in the historical realities of the story, was more interested in participating in a dialogue - with audiences, critics, and other film artists - about the popular tale of China's founding myth. While Tan Dun's opera post-dates Hero, that Zhang directed it evidences that he was not afraid of exploring a different perspective on the same historical story and setting. Furthermore, Hero not only participates in a dialogue with others about the national myth of China's first emperor but it is a sophisticated critique about the role of storytelling in nation building and who controls that discursive power. Shelly Kraicer has asserted that "Hero is a film about storytelling, or, to put it more abstractly, a film that puts narrativity itself into question...Instead of a struggle within narrative, Hero stages a struggle among narratives. It puts control of narrative into question." Dialogue is at the center of the narrative. The struggle between Qin and Nameless, emperor and assassin, in its most simplified description is merely a conversation between characters as they tell and retell each other stories. While this might be an oversimplification, the film is not just a dialogic story, the film is about dialogue. The dialogue in the narrative is a metaphor of the role that Hero has, as a film, in exploring important concepts at the heart of nationalism. As it explores those important concepts - such as heroism, honor, sacrifice, and the relationship between ruler and constituency - the film participates in the dialogue of nationalism while simultaneously critiquing the dynamics of that dialogue. It is about who gets to tell the nation's stories, an investigation of the control of storytelling and the control of the discourse of identity; who controls what is said and the power to define cultural identity.

The dialogic nature of the film narrative as well as the awareness of the cultural familiarity and pre-existing discourse of the historical setting of the film indicates that Hero, then, is not simply Zhang's proposal of 'this is how it was' or 'this is how it is.' It is a 'what if' exploration of national discourse which is played out through the dynamics of a precarious relationship between a tyrannical emperor and an assassin seeking vengeance for past wrongs. The 'what if' explored by Hero involves the portrayal of the China's first emperor and includes the film's titular ideal, another aspect of the film which is misunderstood by the fascist argument. 


\section{Hero's Heroes.}

The title complicates the film's dialogic exploration. Upon first glance the film's title provokes an important question: who is the hero? The fascist argument's answer to that question takes for granted that Nameless is the hero of the film. There are two moments in the film that provide justification for this assumption. First, he is introduced to the emperor's court as the hero. When Nameless arrives at the gates of the palace courtyard there is a long path to the stairs which lead to the building where the emperor waits. On either side of the path is a throng of people, all dressed in black, watching Nameless as he arrives. There to meet Nameless is a magistrate who inspects the 'gifts' that Nameless brings with him to present the emperor: those gifts are the weapons of defeated assassins. The magistrate then announces to the gathered courtiers "today we discover that a hero from our great kingdom of Qin... has single-handedly wiped out the enemy.” The other point of justification is found at the end of the film. After Nameless has been killed, his body is carried by several men that appear to be from the emperor's court. While the procession moves down the streets, superimposed titles read that "the nameless warrior was executed as an assassin, but buried as a hero."

If Nameless is in fact the hero, his actions can be read as heroic. Nameless' main action was, in the climactic moment of the film, that he chose not to kill Qin and instead was killed for the attempt. Evans Chan described the climactic action as the "final epiphany - the assassin(s) must die... ultimately the greatest swordsman submits himself to the emperor's messianic idea by seeking death" (19). However, like the portrayal of China's first emperor, Nameless' character is not simply straight-forward. Believing Nameless' characterization in such a simplified manner makes it appear as though the film advocates sacrifice of the individual for the total rule of the leader. This sacrifice becomes a model of heroism to which all national subjects ought to aspire. But Nameless is not a straight-forward character. Superficially, the film presents Nameless as the hero, such as the magistrates pronouncement at the beginning as well as the concluding epitaph after Nameless is killed. Yet, there are too many ambiguities and ambivalences which problematize identifying Nameless as the film's hero.

With a name like Nameless, ambiguity with the character's identity is explicit and inherent. The film gives very little to establish his identity. An individuals 'given' name is part of a 'given' identity that establishes who a person is, "differentiated from another" (Friese 19). Having no given name, indicates that Nameless' identity is a fluid one. The construction of his identity relies on the stories that are told and retold. The first indication of Nameless' identity is presented at the beginning of the film. In voice-over narration, Nameless introduces himself while sitting in the 
carriage on his way to the palace, he is wearing a prefect's uniform - black robes with Qin insignia on a headband. We see him in medium close up, expressionless, motionless except for the movement of the carriage, and we hear him say:

I was orphaned at a young age and was never given a name. People simple called me Nameless. With no family name to live up to, I devoted myself to the sword. I spent ten years perfecting unique skills as a swordsman. The king of Qin has summoned me to court... for what I have accomplished has astonished the kingdom.

Throughout the film this simple yet vague initial introduction will be challenged, amended, and complicated as the relevance of having the name Nameless plays an important narrative and thematic role.

Having no given name, or no given identity, the name Nameless indicates that the protagonist's identity is a tabula rasa, a blank slate upon which his identity will be inscribed. This is different than a reading which might posit Nameless as representing a figurative, or even literal, everyman; a character that might represent every one, and upon which anyone can project their own identity. The negation inherent in Nameless indicates that the assassin is meant as being without name, without identity. The name Nameless evokes the question of identity. Not a 'nobody' or an 'everybody' but simply an unknown. A great paradox of the film that is difficult to reconcile is that the protagonist, the one occupying the space traditionally held by a story's hero, is filled by a character that is without identity. The hero is unidentifiable. His name is not the only ambiguity which problematizes his position as the hero of the film. With the primary site of his identity unknown, it is his actions and the stories of his actions presented in the narrative that will interpolate his identity.

The dialogue between Nameless and the emperor is the site where Nameless' identity emerges. Since Nameless' identity relies on storytelling, it is ambiguous, fluid, and slippery in its construction. Any attempt to delineate characteristics of his identity requires a consideration of its fluid and tenuous nature. As the stories construct and define his identity they also simultaneously determine the characteristics of his heroism. As such the qualifications of Nameless as hero are as ambiguous and unstable as his identity. Early in the dialogue, Nameless' identity and heroism are first determined by the story which he recites, giving him initial power over his identity. His heroism in this first story is centered on empire and nationalism, protecting and saving the emperor by killing the other assassins. When this story is revealed to be untrue, the emperor tells his version of the story, altering Nameless' identity and the nature of his heroism. This new version shifts Nameless' heroism and re-centers it onto himself, a selfish act of revenge for the annihilation of his 
family by an army under the command of the emperor. Importantly, every action that Nameless is shown or said to have done up to and even including the climactic action, is a facade. These actions are lies fabricated with the sole purpose of constructing an identity with will curry favor with the emperor in order to get close enough to kill him. The presentation of the stories in their spectacular artificial display emphasizes the performative nature of the stories which, because it is performative, compromises and corrupts the authenticity of Nameless' identity (see Larsen 184, 188).

The ambiguity of action involved in the construction of Nameless' identity culminates with the climactic action of the film. This action, and the way it was presented cinematically, epitomizes the ambivalence and ambiguity wrought throughout the film. After Qin surrenders his sword to Nameless - effectively surrendering his life as well - he turns his back to the assassin and awaits his fate. Nameless then takes the sword and executes his special kill maneuver floating across the interstitial space to the emperor. The film cuts to a medium close-up where we are shown Qin, from the torso up, on the right of the screen looking right, away from Nameless. Nameless moves from far left of the screen towards Qin. Instantly after cutting to this shot Qin displays a shocked expression. We cannot see the sword or Nameless' arm and hand, but we are meant to believe that Nameless has stabbed the emperor. Then Nameless quietly utters advice to Qin at which point the camera pans down to reveal that Nameless had harmlessly jabbed the emperor with the pommel of the sword, having turned it around in mid-flight. This shot where we only see the emperor's expression embodies the ambiguity of the film. Did Nameless kill Qin? No, but it looks like he did until it is revealed otherwise.

This climactic action is ambiguous in another way. Is what Nameless accomplishes heroic? Implicit in the fascist argument's criticism is the assumption that the film presents the final action of sacrifice as heroic. The fascist argument has contended against the film's presentation and has interpreted the final act as not heroic, but fascist. As the fascist argument relies on the surrendering of Nameless to the emperor to define his heroism as a fascist one, it provokes the question that if Nameless had successfully killed the emperor, would that action be more heroic? Would that be a heroism that is not fascist? Evans Chan has further alleged that Nameless' grand scheme of surrender was intended from the beginning of his quest. Chan called it the film's "cruel joke" that Nameless is "seeking death" all along (20). The idea that Nameless enters the dialogue with Qin having already decided to surrender is a tenuous hypothesis. If he meant to not kill the emperor, then why seek audience with him? To be a martyr for the kingdom? Nameless had no name, making the idea of intentional martyrdom problematic. Furthermore, there where plenty of victims 
that died for the empire. Those victims can represent the sacrifice required for the glorification of the ideal of unification. The film provides evidence that Nameless had not yet decided whether to kill Qin or abandon his revenge. There is a moment of doubt, a subtle performance cue which is emphasized through the use of a close-up. At one point in the discussion Qin describes his disgust at the disunity inherent in the many incompatible writing systems and expresses to Nameless his commitment to unification and that he plans to continue his bloody conquest. As Qin reveals this, the camera focuses on Nameless whose expression exhibits a shocked terror (see Lee). This indicates that he has not yet decided whether to persist or whether to abandon his plans of assassination. The storytelling mechanism at the center of the narrative structure has an important function here. It provides the process by which Nameless becomes converted to the ideology that Broken Sword imparted to him. The dialogue with the emperor seems a test for determining Qin's worthiness to stay on the throne, whether tian xia - discussed in-depth later - is worth giving up the revenge quest. The little nuances of Jet Li's performance under Zhang's direction seem evidence of a pensive, still indecisive, deliberation. This lack of clear resolve is further evidence that Nameless embodies ambiguity and ambivalence.

The fascist framework interprets Nameless' choice at the climactic action as a sacrifice or a surrender. Importantly, what Nameless does, rather than being a sacrificial action, ought to instead be considered as a deliberate inaction. A central characteristic of the wuxia genre is that the wuxia hero or heroine often displays a reluctance to fight. They are obligated to fight because they know that if they do nothing, they and others will perish. Inaction in the face of opposition means death to the wuxia hero or heroin (Farquhar, "A Touch"169-72). Hero inverts this classic wuxia characteristic, placing preference instead on Daoist transcendence and inaction (see Lee). Nameless occupies the position in the narrative where the hero is traditionally found, he is the volitional protagonist, his narrative and his actions are the catalyst that move the film story forward. Wuxia heroes and heroines in the jianghu are aware of their role in history, consciously righting the wrongs in society, assassinating evil rulers or otherwise fighting wrongdoers fully aware of the historical implications of their actions. Nameless, however, begins his quest selfishly motivated. There is little or no awareness, at least initially, of what his actions will mean historically. His decision to not kill the emperor results in his death, proving that inaction does indeed mean death for the wuxia warrior. Selfish motives and inaction inverts the wuxia ideal of a noble warrior-knight adding more ambiguity and difficulty in ascribing Nameless as the film's hero.

Finally, the ending of the film, which accounts for one of the occasions where the film superficially justifies naming Nameless as the hero, contributes to the ambiguity of Nameless qua 
hero. Just as the eulogy of the emperor carries a hyperbolic resonance (see Lee), the epitaph of Nameless, "executed as an assassin but buried as a hero," also comes across with considerable hyperbole. It is an exaggerated contradiction of juxtaposed ideas that invokes ambiguity and ambivalence. This ambiguity and ambivalence is visually represented in the last shot of the emperor standing alone in his palace just after ordering Nameless' execution. The emperor's expression shows no hint of satisfaction or closure, but dissatisfaction and uncertainty. It is the emperor's moment of doubt. Compounding the ambiguity of the last few shots, Vivian Lee has pointed out that the absence of Nameless' body - not being able to see what happened to him - is a visual cue to the ambivalence of the narrative and filmic presentation. The film does not say 'this is a hero' because the definition is unclear, unsettled, unresolved. It is a dialogic story that offers no answers, remaining in a state of aperture as though to await a dialogic response. With these ambiguities and ambivalences it is therefore problematic to assume that Nameless is straightforwardly the film's hero.

Who, then, is the film's hero? If not Nameless, is it Qin, China's first emperor? Stephen Teo has argued that Qin might be a great candidate for being the hero. He is the only character with power to bring about peace (Chinese Martial 186). Indeed, not just Qin, but most of the characters in the film can potentially be considered as the hero. Jet Li has stated that "Zhang Yimou wanted to explore what kind of person can become [a] hero within the framework of fighting, politics, romance and jealousy. Is it the conquering emperor? The assassins? The killer of the assassins" (qtd. in Eng)? Indeed the ambiguities of the film make it difficult, even problematic, to identify anyone as the hero. Zhang Jia-xuan proposed that in lieu of Hero's ambiguities the film is not about heroes, but about the absence of heroes: "although the king and the warriors, each in his or her own way, all show heroic traits, none can be regarded as a real hero in the full sense of the word, if hero means an ideal model of courage, wisdom, and nobility" (51). The way that Nameless and heroism is repeatedly presented, subverted, and reconstituted indicates that the film is more interested in the discussion, the dialectic, of heroes and heroism than identifying any particular hero, per se.

\section{Hero, Tian Xia, and 'Our Land.'}

The film's dialogic narrative reaches its climax with the expression of tian xia, an ideal in which the film places significant emphasis. The idea first enters the dialogue when Nameless tells the emperor of his encounter with Broken Sword and why Broken Sword had decided not to kill the emperor. In the third retelling of the story, Broken Sword meets Nameless in the desert to persuade 
Nameless to stop his quest to kill the emperor. When Nameless refuses, Broken Sword offers Nameless a 'gift' of two words. In dramatic display, Broken Sword writes those two words in the sand with his sword. We are left to wonder what those words are until Qin asks Nameless to reveal them. "Tian xia," Nameless says, and the emperor repeats them with a sort of reverence. In the English subtitles tian xia is translated as 'our land.' At the end of the film, just before the credits appear on screen the last item that a Western audience sees prior to the film's credits is those words. After the death of Nameless, some of the accomplishments of Qin are enumerated. Then the onscreen text explains that the events in the film were "more than two thousand years ago... But even now when the Chinese speak of their country they call it... Our Land." It is valuable to note that while this investigation is primarily interested in Western reception of the text, it is important to consider the Chinese significance of tian xia as many analyses written about Hero, especially those of the fascist argument, have utilized the Chinese term but do very little to address its inherent complexity.

Tian xia is not a new idea. It has had a multitude of interpretations and practical applications throughout history. The narrative potency ascribed to tian xia, or 'our land,' by the film is such that any analysis of the film ought to consider its historical and contemporary significance. The fascist argument forecloses the complex history of tian xia and conflates tian xia to mean the same for both emperor and assassins (see Chan 20). As such, the ideal serves one purpose only: the justification, even encouragement, of tyrannical rule.

Feng Lan has explained that there are at least two different notable meanings to tian xia. The Confucian use of the word connotes a moralistic ideal of how a ruler, endowed with the Mandate of Heaven, would rule benevolently and unite the people. Most importantly, this sort of ruler is one "whose authority was invested in the will of the people" (Lan 5). In other words, under this formulation, the unification and rule of a nation by one leader places emphasis in the people as primary site for the signification of power. The other prominent use of the word is the Legalist concept. While taking the same goal - ruling the people and unifying the nation - the legalist interpretation of tian xia places emphasis on the supremacy of the ruler. According to this conceptualization, an 'enlightened' ruler should be able to skillfully subjugate 'all under heaven' to himself (ibid. 5). Lan described how Li Si, a Legalist, served the first emperor of Qin and put the Legalist tian xia approach into practice. Lan further argued that Hero is an exploration of the conflicting tensions between the two different interpretations. The emperor embodies the Legalist version, while Nameless and Broken sword are proponents of the Confucian application. Lan's 
conclusion was that Zhang Yimou's film points to the problems of employing tian xia in light of these divergent and radically different interpretations - they are incompatible (ibid. 3, 13, 17-23).

However complex it may be, the translation of tian xia into 'our land' for the English subtitles potentially forecloses the dynamics of the Chinese ideology. In America and to those familiar with American history and ideology, 'our land' resonates with the concept of manifest destiny which, with its inherent focus on geopolitical nationalism, can be interpreted as fascist. For at least American audiences, our land manages to conjure a similarity to the phrasing in one of the most familiar American folk songs: Woody Guthrie's “This Land is Your Land.” In the chorus of that song nationhood is circumscribed by geographical features and membership in the nation-state grants rights of ownership of the land, this serves to inspire nationalistic sentiment:

This land is your land, this land is my land

From California to the New York islands

From the Redwood forest to the gulf stream waters

This land was made for you and me.

It is in connection to this nationalist sentiment that the translation to 'our land' is a fitting one, 'our land' appeals to imperialistic American idealism (Khoo; see also Xu 27). The difficulty in interpreting the film is that 'our land' does not have any direct historical significance in the West outside of the connection to Guthrie's popular folk song. Even with the association to "This land is your land" there is no tradition of speaking of such a notion as having multiple implications. So, it is understandable that a Western viewer might ignore any complexity in the film when it expresses 'our land.' But, even non-Chinese audiences can appreciate the differences of perspectives between the assassins and the emperor.

Even as 'our land,' it is conceivable that the 'our' in the phrase has the potential to be interpreted to support different perspectives, regardless of whether or not there is a direct cultural tradition associate with our land. A citizen declaring possession of 'our land' has different implications than if a politician made the same declaration. The former justifies governance founded on the 'rights' of the people while the latter justifies rule centered on the control and power of the ruler. In Hero the dynamic is preserved. Whether it is rendered as tian xia or 'our land,' the film is very much the same in the cinematic presentation of narrative as well as the performance of the characters regardless of the different translations. Nameless' moment of doubt is a point at which the disharmony of the ideology of the two characters becomes most apparent. As Nameless is yet undecided as to whether he will go through with his plan or whether to abandon it, there is a hint of realization that what Qin is talking about - his plans of applying tian xia - are not conducive 
to what Nameless believes is appropriate (see Lee). Also, at the end of the film, after Nameless walks away from the emperor, Qin has his own moment of doubt. His doubtful indecisiveness rests on whether or not to kill the assassin. Having been enlightened by his contemplation of the 'sword' scroll to a tian xia more compatible with people-centric tian xia, he hesitates to kill Nameless. But, Nameless represents a transgressive national subject - he has already demonstrated, through skillful deceit, that he can move from the peasant sphere to emperor's throne, transgressing ruler-subject boundaries with no difficulty, and that his skills are intended for the death of rulers he lives in the nation but is not ruled by it. Bound by ruler-centric tian xia, Qin is forced to kill Nameless.

Notwithstanding the fascist argument's conflation of tian xia's various meaning, a profound central idea of the film is lost as tian xia is over-emphasized. Many writers have identified tian xia, or 'our land,' as the central theme of the film. For Guan-soon Khoo 'our land' as central theme has perpetuated for him a confusion, or 'mixed feelings,' as to whether the film promotes tyranny or not. This overemphasis on tian xia overshadows Qin's enlightened realization of the "highest ideal of a warrior." Just after Qin has thrown his sword to Nameless, he has his back turned to Nameless as he stares at Broken Sword's calligraphy painting of the twentieth variation of the word 'sword.' After contemplating it for a moment, Qin declares that he has discovered the meaning of the scroll. It does not, as Nameless alleged, reveal techniques of the swordsman, but it does reveal three levels or ideals of a warrior. As Qin explains to Nameless

in the first stage, man and sword become one and each other. Here, even a blade of grass can be used as a lethal weapon. In the second stage, the sword resides not in the hand but in the heart. Even without a weapon, the warrior can slay his enemy from a hundred paces. But the ultimate ideal is when the sword disappears altogether. The warrior embraces all around him. The desire to kill no longer exists. Only peace remains.

Qin's realization is a profound statement that, when taken with the rest of the film, is contrary to the fascist argument that the film embodies and promotes fighting and dying for the exalting of the nation. Instead, the film "glorifies absolute renunciation and perfect non-violence as preconditions for peace" (Kraicer). This indicates that the highest ideal of a warrior, not tian xia, is meant to be central theme of the film, the true grand apotheosis of the narrative and dialogue. This suggests that a tian xia based on the highest ideal of a warrior would be more closely aligned with the people than the emperor. Nameless is most heroic only at the moment he embodies the highest ideal and puts down his sword. 
As Nameless walks away, Qin is pressured by those in his court to execute the assassin. Even though Qin had just discovered a better way to rule, a better way to be - peacefully - it avails him nothing. Perhaps the great tragedy of the film is that the emperor, trapped by the demands of nation building, cannot effectuate his own new philosophical enlightenment. Indeed, the film's Qin is "dwarfed by the trappings of his power" (Taylor qtd. in Eng). The assassins are able to practice the highest ideal but they die doing so, unable to live that way as national subjects. The emperor lives, but is unable to act upon the highest ideal. Peace and nationalism appear to be incompatible, people-centric tian xia and ruler-centric tian xia are incongruous and irreconcilable within the modern emphasis on nation-states.

\section{Hero's Ambiguity.}

As I have found in the deconstruction of some of the readings of the fascist framework, it is clear that an important characteristic of Hero is that it embodies significant ambiguities. Zhang Jiaxuan and Stephen Teo have both refered to the film's ambiguities as its strength, providing the potential for many different profound interpretations of the film's message (Zhang J.; Teo, Chinese Martial 191). The ambiguity means that the fascist framework can interpret the film as an endorsement of contemporary Chinese government promoting fascist ideology. Also, Vivian Lee can discuss the film as manifesting a "complex engagement with the discourse of nationalism" because of ambiguity. And Teo can suggest that "Hero's perceived nationalism is a discursive space of ambiguity that can be deemed transcendent of the concept of nationalism" (Chinese Martial 171). These various, and potentially contradictory readings, are possible because the ambiguity of the film "refuses, or at least destabilizes, closure of meaning" (Lee).

With no fixed meaning, the film's ambiguity permits multiple meanings and multiple interpretations. The potential to read the film allegorically is symptomatic of the ambiguity of the film and the potential it holds for multiple meanings (see Teo, Chinese Martial 191). As allegory, the film can display and deconstruct "the very process of making history, insisting on the ways that deception, self-interest and self-delusion influence not only individuals but also national identities" (Fuchs). Wendy Larsen's allegorical reading of the film's central dialogue has interpreted it as an exposition of the limitations of culturalism's attempt to control the performative discourse of national identity. She defined culturalism as the modern concern of nation-states, "that each nation must have a set of distinct cultural practices, ideas and forms that inspire love and delight in the homeland" (184). By dialoging one with another, Nameless and Qin attempt to exert control over each other so that they might determine the identity, the 'truth.' "Both the assassins 
and the king represent power, but locate the source of their strength in different areas" (Larsen 186). Culture is the foundation of the assassin's power and the state is the source of the emperor's power. The film, then, represents a modern paradox: that you cannot rely on cultural power to present national identity without state power behind it. In fact, Larsen argued that without state power, any attempt to express identity via culture alone is futile, just as Nameless' death by the hand of Qin's guards was a result of Nameless' attempt to embody peace at the expense and in the absence of the sword (see Larsen 194).

It is also possible to extend Wendy Larsen's allegorical reading to interpret the film as a more direct, or literal, allegory of Zhang Yimou's own attempt to present Chinese culture to the world. In this allegorical reading, much like the present thesis, Nameless would represent Zhang, and Qin would be Western writers. Tian xia would then represent the film, Hero, as a vehicle for cultural expression. Therefore, the emperor's misunderstood empire-focused, ruler-centric idea of tian xia would be the misinterpreted, discourse-bound fascist reading of Hero. This interpretation would indicate that, as a film of ambiguities, it is much easier for an audience to read Hero alternatively, taking into account the complex problematics of its relationship to the national, than it is for Qin, tragically bound by the 'temptations of fascism,' to let Nameless live.

Beyond the potential for allegories of cultural expression, the film's ambiguities even facilitate reading a Western religious allegory: the story of Pontius Pilate the trial of Christ found in the King James version of the New Testament. After ideals are exchanged between Nameless and the emperor, Nameless leaves the emperor's throne and walks to the gates of the palace. There he stops and turns to face a horde of the emperor's archers that have positioned themselves on the steps between Nameless. It is apparent that the emperor contemplates letting Nameless go. But his court pleas for the emperor to execute him. They repeat the call several times, "your Majesty. Permission to execute?" After the emperor hesitates, they call out in unison "he conspired to assassinate. This man cannot be trusted! He tried to kill you! Do not spare him! This is the sacred law of Qin! If your majesty is to unite the land, this man has to be made an example of!" Then they continue the call to execute. Finally, reluctantly, the emperor gives the sign to execute Nameless. The circumstances of Nameless' execution and surrender have an allegorical resonance to the account of Christ's trial and subsequent concession to crucifixion. After Pilate shows some hesitance in sentencing Christ, the chief priests cry out "crucify him, crucify him...we have a law, and by our law he ought to die, because he made himself the Son of God" (John 19.6-7). The similarities, while not obvious, per se, are enough to be significant: a leader who hesitates to 
execute an individual whose existence transgresses subjection and threatens the leader's rule, and a group that surrounds the leader and persuades the leader to execute the individual.

Looking at the potential to read the film as both an allegory of expressing culture as well as an allegory of Christ's trial demonstrates that the ambiguity of the film ultimately undermines any attempt to read the film in any fixed or certain manner. The way that Hero is read has a tendency to reveal more about the perspective and discursive persuasion of the viewer than of the filmmaker. What is revealed with the fascist framework is that its reliance on the discourses of authorship and national cinema problematically determines a reading of the film that forecloses other potential meanings. This chapter has explored the fascist framework's problematic assumptions which have foreclosed the film's ambiguity, a strength which makes possible many different meanings. Rather than straight-forwardly promoting fascism as pro-government propaganda, the film explores issues at the heart of nationalism in a complex and open dialogue of ideas presented in an aesthetically spectacular display of narrative. 


\section{Conclusion}

This thesis has explored the discursive construction of Zhang Yimou as an auteur of Chinese national cinema. Through the years, that construction has facilitated a specific predetermined perception of Zhang and his films emphasizing characteristics of the three recurring motifs aesthetically virtuosic, culturally authentic, and politically subversive. In Chapter One, Zhang's career genesis was analyzed, and the emergence of those motifs investigated. In Chapter Two, Hero's release was explored and the fascist framework's response to the film was analyzed and deconstructed which revealed that the three motifs had undergone a discursive shift to support and justify the fascist framework. Because of the hegemonic influence of the discourses of authorship and national cinema, the interpretation of Zhang's films have been bound by the three motifs that these two discourses had previously dictated. In Chapter Three, Hero was re-evaluated through an analysis of the assumptions of the fascist framework. Deconstructing those assumptions emphasized the power of the determining discourses on the reception of the film and how the predetermination that they engendered has led to the foreclosure of alternative interpretation and meaning. Chapter Three's omission of any discussion of the three motifs is, in part, to show that Zhang and his films do not have to be bound by the discourses of authorship and national cinema. When not bound by these discourses, the film has the potential to present its own meaning and is not bound to necessarily manifest the motifs that have recurred over the course of Zhang's career.

In Vivian Lee's analysis of Hero's ambiguities, she suggested that "as an internationally acclaimed auteur with an unusually popular appeal, Zhang represents a successful model of filmmaking, ineluctably bound up with the interplay of economic and sociopolitical forces in the global cultural terrain that necessitate a remapping of the national in terms of the transnational." While it is important to consider the implicit and explicit messages that a film may have about politics or nationalism - as there are many important considerations that must be taken into account regarding a film's relationship to the national - the auto-reading propensity of Western scholarship to read them exclusively in these terms unnecessarily limits the reception and interpretation of a film text.

Analysis conducted here of the presiding frameworks of national cinema and authorship discourses, as well as consideration of alternative readings by other authors, reveals the inadequacies and limitations of existing paradigms and frameworks. When analyzed outside the 
determination of these frameworks, Hero opens up, and facilitates, the potential for more complex and diverse readings and interpretations. Eliminating the Western tendency of applying the biased hermeneutics of national cinema and authorship, eliminating the discursive propensity to auto-read a film from China as political, would clear a space where the potential for new meaning can be found. Hero can thus be rediscovered as a valuable text in an international conversation that continues to find more moments of expression and enables new avenues of exploration. 
Appendix:

\section{Zhang Yimou and His Films.}

Below is a chronology of Zhang Yimou's life and films up until the ceremonies of the Beijing Olympics. Full length motion pictures which Zhang Yimou directed are in bold. To give an idea of the presence that Zhang and his film's had at international film festivals a number of award wins and nominations of each film is included. Significant awards and nominations are listed below the films. ${ }^{15}$

1951 Zhang Yimou Born in Xi'an, China on 14 November.

1969-76 Sent to work on a farm, then a spinning mill for Seven years.

1974 Buys first camera. Some of his photographs are published in Shaanxi Daily.

1978-82 Is enrolled at Beijing Film Academy for training as a cinematographer.

1984 Cinematographer for Zhang Junzhao's One and Eight and Chen Kaige's Yellow Earth.

1985 Cinematographer for Chen Kaige's The Big Parade, award-winning actor in Old Well.

1987 Red Sorghum (Hong gao liang) - 7 wins, 3 nominations.

- Sorghum was awarded Golden Bear at 1988 Berlin Int. Film Festival.

1989 Operation Cougar (Daihao meizhoubao) - 1 win.

1990 Ju Dou - 3 wins, 1 nomination.

- Ju Dou was nominated for an Oscar at the 1991 Academy Awards.

1991 Raise the Red Lantern (Da hong deng long gao gao gua) - 16 wins, 3 nominations.

- Red Lantern was awarded Best film not in the English Language at 1991 BAFTA.

- Red Lantern was awarded Silver Lion at 1991 Venice Film Festival.

- Red Lantern was nominated for an Oscar at the 1992 Academy Awards.

1992 The Story of Qiu Ju (Qiu Ju da guan si) - 15 wins, 1 nomination.

- Qiu Ju was awarded Golden Lion at 1992 Venice Film Festival.

Government ban on Ju Dou, and Raise the Red Lantern is lifted.

\footnotetext{
${ }^{15}$ Gateward was consulted for the biographical information (xiii), and information for awards and nominations were collected from imdb.com.
} 
1994 To Live (Huozhe) - 4 wins, 2 nominations.

- To Live was awarded Best film not in the English Language at 1995 BAFTA.

- To Live was awarded the Grand Prize of the Jury at 1994 Cannes Film Festival.

1995 Shanghai Triad (Yao a yao yao dao waipo qiao) - 4 wins, 3 nominations.

- Triad was awarded Technical Grand Prize at 1995 Cannes Film Festival.

Lumière and Company contribution.

1997 Keep Cool (You hua hao hao shuo) - 1 win, 2 nominations.

- Cool was unexpectedly withdrawn from Cannes by Chinese Government.

1999 Not One Less (Yi ge duo bu neng shao) - 15 wins, 1 nomination.

- Not One Less was awarded the Golden Lion at 1999 Venice Film Festival.

The Road Home (Wo de fu qin mu qin) - 15 wins, 4 nominations.

- Road was awarded the Silver Bear at 2000 Berlin Int. Film Festival.

- Road was awarded the Audience Award at 2001 Sundance Film Festival.

$2000 \quad$ Happy Times (Xingfu shiguang) - 3 wins, 1 nomination.

2002 Hero (Yingxiong) - 26 wins, 19 nominations.

- Hero was nominated for an Oscar at the 2003 Academy Awards.

2004 House of Flying Daggers (Shi mian mai fu) - 18 wins, 37 nominations.

2005 Riding Alone for Thousands of Miles (Qian li zou dan qi) - 4 wins, 6 nominations.

2006 Curse of the Golden Flower (Man cheng jin dai huang jin jia) - 11 wins, 19 noms.

2007 "En Regardant le Film” contribution in To Each His Own Cinema.

2008 Beijing Olympics opening and closing ceremonies. 


\section{Works Cited}

Barboza, David. "Gritty Renegade Now Directs China's Close-Up.” The New York Times. The New York Times, 7 Aug. 2008. Web. 14 July 2009.

Barthes, Roland. Mythologies. New York: Hill and Wang, 2001. Print.

Behind the Scenes: Zhang Yimou. Prod. Jimmy Wang. New York Times Video. 7 Aug 2008. Web. 24 June 2009.

Berry, Michael. Speaking in Images. New York: Columbia UP, 2005. Print.

Berry, Chris and Mary Farquhar. China on Screen: Cinema and Nation. New York: Columbia UP, 2006. Print.

Big Parade. Dir. Chen Kaige. Guangxi Film Studio, 1987. Film.

Bristow, Michael. "Spectators Awed as Games Begin.” BBC News. BBC News, 8 August 2008. Web. 16 Mar. 2009.

Brook, Vincent. "To Live and Dye in China: The Personal and the Political in Zhang Yimou's Ju Dou." CineAction (Winter 2003): 21-9. Print.

Brooks, Xan. "Danny Boyle: From Slumdog to the Olympics." The Guardian. The Guardian, 8 June 2010. Web. 10 June 2010.

Canby, Vincent. “Red Sorghum (1987): Film Festival; Social Realist Fable of 1930's China.” The New York Times. The New York Times, 9 Oct. 1988. Web. 20 Mar. 2009.

Cardullo, Bert. Out of Asia: the Films of Akira Kurasawa, Satyajit Ray, Abbas Kiraostami, and Zhang Yimou. Newcastle: Cambridge Scholars P, 2008. Print.

Caughie, John. Theories of Authorship: A Reader. Boston: Routledge, 1981. Print.

Chan, Evans. "Zhang Yimou's Hero and the Temptations of Fascism.” Film International 2 (2004): 14-23. ProQuest Direct Complete. Web. 10 Feb. 2009.

Chen, Ming-May, and Mazharul Haque. Representation of the Cultural Revolution in Chinese Films by the Fifth Generation Filmmakers: Zhang Yimou, Chen Kaige, and Tian Zhuangzhuang. Lewiston: Edwin Mellen, 2007. Print.

Chow, Rey. Primitive Passions: Visuality, Sexuality, Ethnography, and Contemporary Chinese Cinema. New York: Columbia UP, 1995. Print.

Clark, Paul. Reinventing China: A Generation and Its Films. Hong Kong: Chinese UP, 2005. Print.

Corliss, Richard. "The Fire in Her Eyes.” Time. Time, 26 Apr. 1993. Web. 22 July 2009. 
Corrigan, Timothy. "The Commerce of Auteurism.” Film and Authorship. Ed. Virginia Wright Wexman. New Brunswick: Rutgers UP, 2003.96-111. Print.

Curse of the Golden Flower. Dir. Zhang Yimou. Beijing New Picture, 2006. DVD.

D'Lugo, Marvin. “Transnational Film Authors and the State of Latin American Cinema.” Film and Authorship. Ed. Virginia Wright Wexman. New Brunswick: Rutgers UP, 2003. 112-30. Print.

Dyer, Richard. Stars. London: BFI, 1982. Print.

Ebert, Roger. “Hero.” Chicago Sun-Times. Chicago Sun-Times, 27 Aug. 2004. Web. 22 July 2009.

---. "Red Sorghum.” Chicago Sun-Times. Chicago Sun-Times, 28 Feb. 1989. Web. 22 July 2009.

The Emperor and the Assassin. Dir. Chen Kaige. Shin Corporation, 1998. DVD.

The Emperor's Shadow. Dir. Xiaowen Zhou. Xi'an Film Studio, 1996. DVD.

“En Regardant le Film.” Dir. Zhang Yimou. To Each His Own Cinema. Cannes Film Festival, 2007. DVD.

Eng, Y. Robert. "Is Hero a Paean to Authoritarianism?" Asia Media. 9 July 2004. Web. 27 Apr. 2009.

Farquhar, Mary. "A Touch of Zen: Action in Martial Arts Movies.” Chinese Films in Focus: 25 New Takes. Ed. Chris Berry. London: BFI, 2005. 167-74. Print.

---. “Zhang Yimou.” Senses of Cinema 20 (May-June 2002): n. pag. Web. 27 Apr. 2009.

Flowers Beneath the High Mountains. Dir. Jin Xie. Shanghai Film Studios, 1984. Film.

Foucault, Michel. "What is an Author." The Foucault Reader. Ed. Paul Rabinow. New York:

Pantheon, 1984. 101-120. Print.

Friese, Heidrun. "Identity: Desire, Name and Difference." Identities: Time, Difference and Boundaries. Ed. Heidrun Friese. New York: Barghahn, 2002. 17-31. Print.

Fuchs, Cindy. "Fighting for Truth.” Philadelphia City Paper. Philadelphia City Paper, 26 Aug.-1 Sept. 2004. Web. 4 Jan. 2010.

Gateward, Francis. Zhang Yimou Interviews. Jackson: UP of Mississippi, 2001. Print.

Guthrie, Woody. "This Land is Your Land.” The Asch Recordings. Smithsonian Folkways Recordings, 1999. CD.

Happy Times. Dir. Zhang Yimou. Guangxi Film Studio, 2000. DVD.

Hayward, Susan. Cinema Studies: The Key Concepts: Third Edition. New York: Routledge, 2006. Print.

Hero. Dir. Zhang Yimou. Miramax, 2002. DVD.

“Hero.” IMDb: The Internet Movie Database. IMDb. Web. 15 Feb. 2009. 
Hoberman, J. "Man With No Name Tells Story of Heroics, Color Coordination.” The Village Voice. The Village Voice, 17 Aug. 2004. Web. 20 July 2009.

The Holy Bible (KJV). SLC: Church of Jesus Christ of LDS, 1989. Print.

Hinson, Hal. "Red Sorghum." The Washington Post. The Washington Post, 21 Oct. 1988. Web. 17 Sept. 2009.

House of Flying Daggers. Dir. Zhang Yimou. Beijing New Picture, 2004. DVD.

Howe, Desson. "Red Sorghum.” The Washington Post. The Washington Post, 21 Oct. 1988. Web. 17 Sept. 2009.

IMDb: The Internet Movie Database. IMDb. Web. 15 Feb. 2009.

Jiao, Xiongping. "Discussing Red Sorghum." Zhang Yimou Interviews. Ed. Francis Gateward. Jackson: UP of Mississippi, 2001. 3-14. Print.

Ju Dou. Dir. Zhang Yimou. China Film, 1990. DVD.

Keep Cool. Dir. Zhang Yimou. Guangxi Film, 1997. Film.

Khan, Joseph. "An Emperor is Reinvented, A Director is Criticized." The New York Times. The New York Times, 2 Jan. 2003. Web. 14 July 2009.

Khoo, Guan-Soon. "Hero.” Offscreen.com 11.5 (May 2007): n. pag. Web. 18 May 2009.

Kong, Haili. "Symbolism Through the Subversive Lens in His Early Films." 100 Years of Chinese

Cinema: A Generational Dialogue. Eds. Haili Kong and John Lent. Norwalk: Eastbridge, 2006. 115-30. Print.

Kraicer, Shelly. “Absence as Spectacle: Zhang Yimou's Hero.” Cinema Scope Magazine 5.1 (Spring 2003). Print.

Kung Fu Hustle. Dir. Stephen Chow. 2004. DVD.

Lan, Feng. "Zhang Yimou's Hero: Reclaiming the Martial Arts Film for 'All Under Heaven'.” Modern Chinese Literature and Culture 20.1 (Spring 2008): 1-43. Print.

Larsen, Wendy. “Zhang Yimou's Hero: Dismantling the Myth of Cultural Power.” Journal of Chinese Cinemas 2.3 (2008): 181-96. Print.

Lau, Jenny Kwok Wah. “Hero: China’s Response to Hollywood Globalization.” Jump Cut 49 (Spring 2007): n. pag. Web. 24 July 2009.

---. “Ји Dou: An Experiment in Color and Portraiture in Chinese Cinema." Cinematic Landscapes: Observations on the Visual Arts and Cinema of China and Japan. Eds. Linda Ehrlich and David Desser. Austin: U of Texas P, 1994. 127-48. Print.

Lee, Vivian. "Into/Out of the Critical Divide: The Indeterminacy of Hero." Scope 9 (Oct. 2007): n. pag. Web. 27 Apr. 2009.

Li, Erwei. "Paving Chinese Film's Road to the World." Zhang Yimou Interviews. Ed. Francis Gateward. Jackson: UP of Mississippi, 2001. 74-98. Print. 
Lu, Sheldon. "Chinese Film Culture at the End of the Twentieth Century: The Case of Not One Less." Chinese-Language Film: Historiography, Poetics, Politics. Eds. Sheldon Lu and Emilie Yeh. Honolulu: U of Hawaii P, 2005. 120-37. Print.

---. "Historical Introduction: Chinese Cinemas (1896-1996) and Transnational Film Studies." Transnational Chinese Cinemas. Ed. Sheldon Lu. Honolulu: U of Hawaii P, 1997. 1-31. Print.

---. "National Cinema, Cultural Critique, Transnational Capital: The Films of Zhang Yimou." Transnational Chinese Cinemas. Ed. Sheldon Lu. Honolulu: U of Hawaii P, 1997. 105-136. Print.

---. “Zhang Yimou.” Fifty Contemporary Filmmakers. Ed. Yvonne Tasker. New York: Routledge, 2002. 412-8. Print.

Lumière and Company. Cinétévé, 1995. DVD.

McNab, Geoffery. "Film: Festival Watch: Berlin Zhang Yimou's Sympathetic Portrait of a Despot is Causing Quite a Stir." The Independent. The Independent, 14 Feb. 2003. Web. 14 July 2009 .

Morris, Meaghan. "Tooth and Claw: Tales of Survival and Crocodile Dundee." Universal Abandon: The Politics of Postmodernism. Ed. Andrew Ross. Edinburgh: Edinburgh UP, 1988. 105-27. Print.

Neo, David. "Red Sorghum: A Search for Roots.” Senses of Cinema 28 (Sept.-Oct. 2003): n. pag. Web. 10 June 2009.

Nichols, Bill. Movies and Methods: An Anthology, Vol. 1. Berkeley: U of California P, 1976. Print. Not One Less. Dir. Zhang Yimou. Beijing New Picture, 1999. DVD.

Old Well. Dir. Wu Tian-Ming. Xi'an Film Studio, 1986. Film.

One and Eight. Dir. Zhang Junzhao. 1983. Film.

Operation Cougar. Dir. Zhang Yimou. 1989. Film.

Palmer, Augusta. "Zhou Xiaowen on The Emperor's Shadow." Industrycentral.net. WEB. 25 May 2009.

Projansky, Sarah, and Kent Ono. "Making Films Asian American: Shopping for Fangs and the Discursive Auteur." Authorship and Film. Eds. David A. Gerstner and Janet Staiger. New York: Routledge, 2003. 263-80. Print.

Raise the Red Lantern. Dir. Zhang Yimou. China Film Co-Production, 1991. DVD.

Rayns, Tony. "The New Chinese Cinema: An Introduction.” King of the Children. London: Faber, 1989. Print.

Red Sorghum. Dir. Zhang Yimou. Xi'an Film, 1987. DVD.

Riding Alone for Thousands of Miles. Dir. Zhang Yimou. Beijing New Picture, 2005. DVD. 
The Road Home. Dir. Zhang Yimou. Guangxi Film, 2000. DVD.

Shanghai Triad. Dir. Zhang Yimou. Alpha Films, 1995. DVD.

Shih, Shu-mei. Visuality and Identity: Sinophone Articulations Across the Pacific. Berkeley: U of California P, 2007. Print.

Smith, Neil. “Cannes Keeps Faith with Auteurism.” BBC News. 12 May 2009. Web. 18 May 2009.

Sontag, Susan. "Fascinating Fascism." The New York Review of Books. The New York Review of Books, 6 Feb. 1975. Web. 13 Jan. 2010.

Spielberg, Steven. "Zhang Yimou.” Time. Time, 17 Dec. 2008. Web. 14 July 2009.

Staiger, Janet. “Authorship Approaches.” Authorship and Film. Eds. David A. Gerstner and Janet Staiger. New York: Routledge, 2003. 27-57. Print.

Stone, Alan. "Where Have All the Heroes Gone?" Psychiatric Times 22.1 (Jan. 2005): 13-6.

ProQuest Social Science Journals. Web. 21 May 2009.

The Story of Qiu Ju. Dir. Zhang Yimou. Sil-Metropole, 1992. DVD.

Teo, Stephen. Chinese Martial Arts Cinema: The Wuxia Tradition. Edinburgh: Edinburgh UP, 2009. Print.

Tempest, Rone. "Zhang Still at the Heart of Chinese Filmmaking." Zhang Yimou Interviews. Ed. Francis Gateward. Jackson: UP of Mississippi, 2001. 63-66. Print.

Thakur, Manavendra. "Red Sorghum Flawed Despite Striking Imagery and Cinematography."

The Tech 21 Mar. 1989: 17. Print.

To Each His Own Cinema. Cannes Film Festival, 2007. DVD.

To Live. Dir. Zhang Yimou. Shanghai Film Studios, 1994. DVD.

Triumph of the Will. Dir. Leni Riefenstahl. Leni Riefenstahl-Produktion, 1935. DVD.

Wartenberg, Thomas, and Angela Curran. "Part 3: Do Films Have Authors?" The Philosophy of

Film. Eds. Thomas Wartenberg and Angela Curran. Oxford: Blackwell, 2005. Print.

Wollen, Peter. "From Signs and Meaning in the Cinema." Film Theory and Criticism: Introductory Reading: Sixth Edition. Eds. Leo Brady and Marshall Cohen. Oxford: Oxford UP, 2004. 565-80. Print.

Xu, Gary. Sinascape: Contemporary Chinese Cinema. New York: Rowman \& Littlefield, 2007. Print.

Yau, Esther. "Yellow Earth: Western Analysis and a Non-Western Text." Film Quarterly 41.2 (1987-8): 22-33. JStor. Web. 13 Oct. 2009.

Yellow Earth. Dir. Chen Kaige. Guangxi Film, 1984. DVD.

Zhang, Jia-xuan. "Hero.” Film Quarterly 58.4 (Summer 2005): 47-52. Print. 
Zhang, Xudong. Chinese Modernism in the Era of Reforms: Cultural Fever, Avant-Garde Fiction, and the New Chinese Cinema. Durham: Duke UP, 1997. Print.

---. "Cinema of Postsocialism: Zhang Yimou's Film Production in the Late 1990s." 100 Years of Chinese Cinema: A Generational Dialogue. Eds. Haili Kong and John Lent. Norwalk: Eastbridge, 2006. 131-67. Print.

---. Postsocialism and Cultural Politics: China in the Last Decade of the Twentieth Century.

Durham: Duke UP, 2008. Print.

Zhang, Yingjin. Chinese National Cinema. New York: Routledge, 2004. Print.

---. Screening China. Ann Arbor: U of Michigan, 2002. Print.

Zhen, Ni. Memoirs of the Beijing Film Academy: The Genesis of China's Fifth Generation. Trans. Chris Berry. Durham: Duke UP, 2002. Print.

Zhu, Ying. Chinese Cinema During the Era of Reform: The Ingenuity of the System. Westport: Praeger, 2003. Print. 